\title{
Dative antecedents for reflexives and pronouns
}

\author{
JACEK WITKOŚ* (D) and PAULINA ŁȨSKA
}

Faculty of English, Adam Mickiewicz University, Poznań, Poland

Received: May 8, 2019 • Accepted: March 18, 2020

(c) 2020 Akadémiai Kiadó, Budapest

\begin{abstract}
This paper aims to advance a comprehensive theory of binding, which can account for all binding patterns found in Polish, some of which are particularly puzzling for traditional and novel formulations of Binding Theory. Namely, Polish reflexive pronouns/possessives are typically (nominative) subject oriented but they can also have dative Object Experiencers, OEs, as antecedents. Yet, OEs are also appropriate local antecedents for pronominal possessives. Our analysis explains the complementarity of pronouns and reflexives and lack thereof by assuming that the Spell-out form of the reflexive/pronoun is determined by its covert movement, while a binding dependency is established via Agree for [var(iable):_] feature.
\end{abstract}

\section{KEYWORDS}

binding, psych verbs, dative antecedents, dative Object Experiencers, reflexivization

\section{INTRODUCTION AND KEY DATA POINTS}

A-binding has been a chief area of research in comparative linguistics since the 80s and 90s (Chomsky 1981, 1986; Manzini \& Wexler 1987, Belletti \& Rizzi 1988; Rappaport 1986; Willim 1989; Hellan 1988; Burzio 1996; Progovac 1992, 1993; Avrutin 1994, among others) when the foundations for the modern theory of binding were laid. It very soon transpired that binding phenomena are subject to parametric differences involving such notions as the size of the binding domain, the morphology of the anaphoric element and the choice of the privileged binder. This paper touches upon the last aspect of the parametric

\footnotetext{
*Corresponding author. E-mail: wjacek@amu.edu.pl
} 
difference, namely subject orientation of anaphors in Polish (and other Slavic languages) as well as certain conditions which dative arguments must meet to qualify as binders; it turns out that even when they happen to be supreme arguments in particular argument structures, they do not fully mimic the behaviour of nominative subjects as binders.

Polish is a subject-oriented binding language, and objects, either dative or accusativemarked ones, cannot bind anaphors in other object/adjunct positions (Rappaport 1986; Willim 1989; Reinders-Machowska 1991 for almost identical data in Russian), as presented in (1). ${ }^{1}$
a. $\operatorname{Jan}_{1}$
opowiedział $\mathrm{Marii}_{2} \quad$ [o
sobie $_{1,{ }^{* 2}} /$ ?niej $_{2}$ (samej)/*nim $]$.
Jan.NOM told
Maria.DAT about self
/ her (alone)/ him
'Jan told Maria about himself/her.'
b. $\operatorname{Jan}_{1}$ pokazał Marii 2 [swoje ${ }_{1, * 2} /$ jej $_{2} /{ }^{*}$ jego $_{1}$ zdjęcie].
Jan.NOM showed Maria.DAT self /her / his picture.ACC
'Jan showed Maria his/her picture.'

Both the reflexive pronoun and the reflexive possessive seem to be oriented towards the nominative subject, while dative (and also accusative) objects are infelicitous binders in (1). At the same time there is evidence from variable binding that the relation of c-command holds between both objects, in line with their surface order and irrespective of their case marking:
a. Jan
pokazał [każdem
zawodnikowi
$\left[\mathrm{jego}_{1}\right.$
nowego trenera].
Jan.NOM showed every player.DAT
his new
coach.ACC
'Jan showed every player his new coach.'
b. Jan pokazał [każdego trenera $]_{1}$ jego $_{1}$ nowym zawodnikom].
Jan.NOM showed every coach.ACC his new players.DAT
'Jan showed every coach to his new players.'

\footnotetext{
${ }^{1}$ A reviewer for Acta Linguistica notices that when the pronoun nim 'him' in (1a) is emphasized by sam 'alone' and the noun $z$ djęcie 'picture' in ( $1 \mathrm{~b})$ is modified by an adjective własne 'own', as in 'his own picture', the coreferent reading between the pronoun and the subject is acceptable. The reason for this effect could be that the addition of a modifier with reflexive-like semantics to a pronoun may be considered as a strategy to form lexical reflexives, as proposed in Reuland (2011). If this is the case, a pronoun plus an emphatic adjective should count as a secondary reflexive, which would explain why, unlike a lone pronoun, it can be bound by the subject. However, since the primary reflexivisation strategy is preferred, the use of reflexives in this context is still more acceptable. As will became clearer later in the text, under our analysis, the dependent element with a variable feature and a $\varphi$-feature of the subject must be lexicalized as a reflexive, be it a reflexive or a secondary reflexive (a pronoun emphasized by sam). Some supporting evidence for treating this emphasis as a secondary or a repair reflexivisation strategy is provided in an experimental study reported in Gogłoza et al. (forthcoming-a) and discussed in more detail in Witkoś et al. (forthcoming) in the context of object coreference in Polish Double Object Constructions, where it is shown that a higher object can be an antecedent for a lower object only when the lower object is lexicalized as a secondary reflexive (a pronoun plus sam 'alone') (see also fn. ${ }^{17}$ ). This work was based on previous studies of the German adverb selbst 'self s' (Reis 1976; Primus 1992; Featherston 2002) which aimed to establish its status as either a focus adverb or an emphatic reflexive. The reader is referred to these works for more details.
} 
Unlike object datives, dative arguments in certain constructions referring to psychological states function as antecedents to anaphoric pronouns (3a). However, they optionally function as antecedents to either pronominal or reflexive possessives $(3 \mathrm{~b})$ :
a. Marii $_{1}$ było żal
siebie $_{1} /{ }^{*}$ ?jej $_{1} \quad$ (samej).
Maria.DAT was.3.SG.N sorrow.3.SG.M self.GEN ${ }^{\star}$ ?her.GEN (alone)
'Maria felt sorry for herself.'

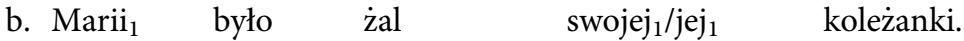
Maria.DAT was.3.SG.N sorrow.3.SG.M self s.GEN/her.GEN friend.3.SG.F.GEN
'Maria felt sorry for her female friend.'

Furthermore, there is a split between (usually non-verbal) predicates with a DAT OE licensing another argument in the genitive and (usually verbal) predicates with a DAT OE licensing an argument in the nominative. The former pattern is shown in (3). In contrast, the verbal psychological predicate podobać się 'appeal to' shows a varied behaviour: the possessive pronoun in the nominative argument is strongly preferred to the possessive reflexive, when bound, as in (4). However, Witkoś (2008) and Witkoś et al. (forthcoming) show that a preverbal DAT OE can be involved in anaphoric binding of an element bearing a case different from nominative but embedded in the nominative-marked constituent, see (5): ${ }^{2}$

(4) Marii $_{1}$ spodobała się ?*$^{*}$ swoja $_{1} / \mathrm{jej}_{1}$ nowa sukienka.

Maria.DAT liked REFL ?* self's/her new dress.NOM

'Maria liked her new dress.'

(5) $\left[\right.$ Nowakom $\left._{2}\right]$ spodobała się $\left[\begin{array}{lllll}\text { nowa książka } & \left(\text { Kowalskich }_{1}\right) & \text { o } & \text { sobie }_{1,2}\end{array}\right.$

Nowaks.DAT liked REFL new book.NOM (Kowalskis') about self

'The Nowaks liked the new book (by the Kowalskis) about themselves/them.'

Examples (3-5) exemplify a most alarming property of DAT OEs in Polish: they function as antecedents to both reflexive and pronominal possessives which are indexically dependent on them. In terms of the classical Binding Theory of Chomsky (1981, 1986; Manzini \& Wexler 1987) they seem to 'bind' both reflexive and pronominal possessives in the same syntactic domain. This is a problem for the view that pronouns and reflexives remain in complementary distribution (Chomsky 1981). ${ }^{3}$

Moreover, there is evidence that the dependency between the pronominal possessor and the DAT OE is not accidental co-reference, as this option is also available in equivalent examples

\footnotetext{
${ }^{2}$ A detailed analysis of dative object experiencers of both verbal and non-verbal psychological predicates remains beyond the scope of this contribution. See Jiménez-Fernández and Rozwadowska (2016) and Bondaruk, Rozwadowska and Witkowski (2017), Bondaruk and Rozwadowska (2018) for recent analyses.

${ }^{3}$ The key Principles of Binding Theory are formulated in Chomsky (1981: 188) as follows:

A. Anaphors must be bound in their binding domains.

B. Pronouns must be free in their binding domains.

C. R-expressions must be free everywhere.
} 
with QPs as antecedents. This confirms the dependent identity (bound variable) readings of the pronominal possessors:
a. Każdemu studentowi $i_{1}$ było żal
żal siebie $_{1}{ }^{\star}$ ?.jego $_{1}$ (samego).
every student.DAT was.3sg.N sorrow.3SG.M self $/{ }^{\star}$ him (alone)
'Every student felt sorry for himself.'
b. Każdemu studentowi ${ }_{1}$ było żal swojej $_{1} /$ jej $_{1}$ koleżanki.
every student.DAT was.3sG.N sorrow.3sG.m self s/her friend.3sG.F.GEN
'Every student felt sorry for his female friend.'

Furthermore, when the ellipsis test is applied to these constructions to check for sloppy identity readings, which indicate an anaphoric dependency (as in Hicks 2009 and Safir 2014), it turns out that the sloppy identity reading is available with both the reflexive and the pronominal possessive in $\left(7 \mathrm{a}^{\prime}\right)$ and $\left(7 \mathrm{~b}^{\prime}\right)$. The fact that sloppy identity readings with pronominal possessives are available is especially interesting in view of the fact that, unlike English, the lexicon of Polish has both a reflexive and pronominal forms for possessives, with the former chiefly used to signal indexical dependency and expected with sloppy readings $\left(\mathrm{a}^{\prime}, \mathrm{b}^{\prime}\right.$ and $\mathrm{b}^{\prime \prime}$ refer to interpretations of the elided VP including the reflexive/possessive pronoun).
$\begin{array}{lllllll}\text { a. } \text { Marii }_{1} \text { było żal } & \text { swojej }_{1} & \text { koleżanki } & \text { i } & \text {Zosi }_{2} & \text { też. }\end{array}$ Maria.DAT was sorrow self's friend.gen and Zosia.DAT too 'Maria was sorry for her friend and so was Zosia.'
$a^{\prime}$. Maria.DAT [VPa was sorrow [self's friend.GEN]] and Zosia.DAT [vpe was sorrow [self's friend.GEN]] too 'Maria was sorry for her own friend and Zosia was sorry for her own friend too.'
b. Marii $_{1}$ było żal jej $_{1}$ koleżanki i $Z_{0 s i}$ też. Maria.DAT was sorrow her friend.gen and Zosia.DAT too 'Maria was sorry for her friend and so was Zosia.'
$\mathrm{b}^{\prime}$. Maria.DAT [vPa was sorrow [self's friend.GEN]] and Zosia.DAT [vPe was sorrow [self's friend.GEN]] too 'Maria was sorry for her own friend and Zosia was sorry for her own friend too.'
$\mathrm{b}^{\prime \prime}$. Maria.DAT [VPa was sorrow [self s friend.GEN]] and Zosia.DAT [vPe was sorrow [her friend.GEN]] too.
'Maria was sorry for her own friend and Zosia was sorry for her friend too.'

The summary of the empirical picture emerging from these data is as follows:

(8) Anaphoric binding in ditransitive constructions in Polish:

The nominative subject acts as an antecedent for (i) reflexive pronouns and (ii) reflexive possessives. The (superior) object (either dative or accusative) cannot act as an antecedent for a reflexive pronoun/reflexive possessive in the other object. The superior object acts as an antecedent for a pronominal possessive in the other object. 


\section{(9) Anaphoric binding in constructions with DAT OE:}

DAT OE acts as an antecedent for: (a) reflexive pronouns; (b) reflexive possessives and (c) pronominal possessives. The DAT OE only very marginally acts as an antecedent for reflexive possessives embedded in nominative constituents. ${ }^{4}$

It seems that the classical binding theory collapsed two related but not isomorphic phenomena: the dependent identity relations relevant for LF interpretation and the lexicalization of the dependent identity relation on the dependent element, relevant at the PF interface. For instance, in (1-2) above the superior object functions as an antecedent for a possessive element in a local domain (it binds it in the LF-relevant sense) but the possessive is lexicalised as a pronominal despite being both indexically dependent on the superior object and being c-commanded by it.

In (3)-(5) and (7) above the DAT OE functions as antecedent for possessives whose identity and interpretation at LF depends on the DAT OE. These possessives can be lexicalised either as reflexive or pronominal. However, the nominative antecedent in (1) can function as an antecedent only for the reflexive possessive. Below we propose an account that captures the condition relevant for both the LF (indexical identity) and PF (lexicalisation) aspects of anaphoric binding in Polish. The condition in question is phase-internal c-command by an antecedent in its case position, computed independently for both the LF- and PF-relevant aspects of anaphoric binding.

We construct our account by developing and updating an approach to binding based on Nikolaeva's (2014) Index Raising (IR). In view of the data in (2) and (4), our goal is to explain why dative antecedents in constructions with psychological verbs ${ }^{5}$ (example $2 \mathrm{~b}$ ) allow for the option of binding both reflexive and pronominal possessives, while the nominative antecedent in transitive constructions allows only for the reflexive possessive variant. We submit that these different binding properties arise because the nominative and dative antecedents occupy different positions, namely

\footnotetext{
${ }^{4}$ This state of affairs is best captured by observations voiced in Safir (2014) on dependent identity readings in VP-ellipsis. In different languages the depenedent identity readings seem to be available in local domains with reflexive and pronominal forms in the antecedent VP. Safir (2014:106-107) submits that the same account of identity readings carries over to the most indexically dependent form (called D-bound, see the definition in (12)) realized morphologically as reflexive:
}

(i) Zelda [vPa judges herself] more harshly than I ever do [vP e].

(ii) Zelda [vpa judges D-bound+3fsg] more harshly than I ever do [vp judge D-bound]

(iii) Zelda [vpa judges D-bound+3fsg] more harshly than I ever do [vp judge 3fsg]

The sloppy reading in (ii) results from the copying of the D-bound itself, while the strict reading in (iii) results from the copying of the $\varphi$-features of the D-bound only, which amounts to a regular pronoun.

${ }^{5} \mathrm{~A}$ reviewer points out that a more precise term to use for predicates which allow for both reflexives and pronouns to be bound by a dative antecedent would be 'non-verbal psych predicates'. While it is true that most of the predicates allowing for this peculiar binding pattern are non-verbal, there are also verbal psych predicates with dative binders which show this pattern, as e.g. the verb brakować 'to miss' in (i). The most crucial property of these predicates (both verbal and non-verbal) which allows them to antecede reflexives is that they take non-nominative theme arguments (see the discussion on Anaphor Agreement effect in section 5).

(i) Marii $_{1}$ brakowało swojej ${ }_{1} / \mathrm{jej}_{1}$ siosty.

Maria.DAT missed self s.GEN/her.GEN sister.GEN

'Maria missed her sister.' 
[spec, TP] and [spec, $v \mathrm{P}$ ], respectively. We also claim that data such as (4), though plentiful, are encumbered with an additional complicating factor in the form of the Anaphor Agreement Effect (AAE, Rizzi 1990; Progovac 1992, 1993; Woolford 1999; Reuland 2011) and they deserve a slightly different treatment. The most straightforward diagnostics for determining the binding potential of the dative argument involves cases when it binds (into) non-nominative elements (so (3) rather than (4)).

The paper is organized as follows. In section 2, we present an outline of our theory of binding, inspired by the Index Raising theory articulated in Nikolaeva (2014), modified in line with Hicks (2009), Safir (2014) and Despić (2011, 2013, 2015). Sections 3 and 4 provide our account of binding in structures with dative arguments. We show why the dative argument of the ditransitive verb cannot function as an antecedent to reflexive elements, although reflexives are indexically dependent on it. Next, we analyse the position and binding options of the DAT OE with respect to other nonnominative dependants of psychological predicates. We further discuss the Anaphor Agreement Effect, its extensions and consequences in section 5. Section 6 concludes the paper.

\section{COMPONENTS OF THE ANALYSIS}

Early on it was observed that the complementary distribution expected of anaphors and pronouns did not hold internal to the nominal projection:
a. They ${ }_{1}$ like [each other's books]
b. They ${ }_{1}$ like [their ${ }_{1}$ books]
a. John ${ }_{1}$ heard [a story about himself ${ }_{1}$ ]
b. $\operatorname{John}_{1}$ heard $\left[\left(\mathrm{PRO}_{2}\right)\right.$ a story about him 1

In the examples above both the anaphors and the pronouns can be interpreted as coreferential with their local antecedents. If the governing category/binding domain were defined in identical terms for both the pronoun and the reflexive (and both required an accessible SUBJECT), (10b) and (11b) should constitute violations of Condition B, with clausal subjects binding the pronouns. (11) Could be rescued if $\mathrm{PRO}_{2}$ were posited in the [spec, DP] position, as suggested in Chomsky (1982). The problem of non-complementarity distribution was solved, at least for English, through the notion of the Complete Functional Complex (CFC) in Chomsky (1986) ${ }^{6}$ and Manzini and Wexler (1987). ${ }^{7}$ The CFC implies that pronouns and anaphors have domains which partly overlap (clauses) and the requirement of having an accessible SUBJECT applies to anaphors but not pronouns. Hence the NP in (10) is a binding domain for the pronoun, in which it is free, while it is not a binding domain for the anaphor; the clause is, with AGR as the accessible SUBJECT. However, a more careful scrutiny of the Polish data in (1-3) above reveals that we are not looking at facts reducible to the difference between NP as a binding domain for pronouns in its specifier

\footnotetext{
${ }^{6}$ Following the lead in Huang (1983), Chomsky (1986: 169) defines the Complete Functional Complex (CFC) in the following manner: CFC is a minimal category such that all grammatical functions compatible with its head are realized in it - the complements, necessarily, by the projection principle, and the subject, which is optional unless required to license a predicate.

${ }^{7}$ Manzini and Wexler (1987: 421) assume the following notion of the governing category/binding domain: $\gamma$ is a governing category for $\alpha$ if $\gamma$ is the minimal category that contains $\alpha$ and a governor for $\alpha$ and can have a subject $\beta$ or, for $\alpha$ anaphoric, has a subject $\beta, \beta \neq \alpha$; if, for $\alpha$ anaphoric, $\beta$ is accessible to $\alpha$.
} 
position and NP as an incomplete CFC for anaphors in this position. If this were so, identical effects to (10), so crucially optionality between pronominal and reflexive possessives, would be expected of all types of antecedents: nominative subjects, dative OEs and superior dative objects. Yet this is not the case: only dative OEs show this optionality. Optionality is available neither to nominative subjects (strictly requiring coreferential reflexive possessives in this context) nor to superior dative objects (strictly requiring coreferential pronominal possessives in this context).

We propose that the set of phenomena traditionally referred to as anaphoric binding needs to be separated into two connected but not isomorphic aspects: the LF relevant one and the PF relevant one. The former concerns the relation of indexical dependency formed between the antecedent and the form that indexically depends on it (Safir 2004). The latter concerns the lexicalisation of the most indexically dependent form. While the classical binding theory (the CBT of Chomsky 1981, 1986, 1993) collapses the two notions, we would like to keep them separate and propose that the most identity dependent form, be it anaphoric, personal or possessive, is overlaid with lexical content late in the derivation, at Spell-Out. ${ }^{8}$ It is introduced into the Initial Numeration as an undefined element, the most dependent form, called D-bound in Safir (2014) or the Index in Nikolaeva (2014). Safir (2014: 91-92) defines the properties of D-bound/Index, in the following way:

(12) a. Always a variable: D-bound is the same object in SEM (the syntactic input to semantic interpretation) in all cases; it is interpreted as a bound variable regardless of its $\varphi$-features.

b. Always A-bound: the binder of D-bound (its antecedent) must c-command it from an A-position; that is, the D-bound form is A-bound.

c. Always feature compatible: D-bound must be feature compatible with its antecedent (informally, this property may be termed antecedent agreement).

d. Spell-Out of the morphological shape of D-bound is potentially sensitive to whether A-binding is phase internal:

e. Agreement compatible with morphological shape may be determined by phase internal factors locally distinct from antecedent agreement;

f. Anywhere phase-internal shape is not required, D-bound receives default pronominal shape.

Conditions (12b), (12d-e) predict that a D-bound/Index in a local, phase-internal c-command relation with its antecedent takes on a morphological form of an anaphor, while a D-bound/Index further removed from or not c-commanded by the antecedent spells out as a pronoun.

Thus, potentially, a D-bound/Index can be indexically dependent on its antecedent under ccommand in the LF-relevant representation but it can at the same time be lexicalised as a pronoun when the c-command condition does not hold of the PF-relevant representation or the antecedent is phase external. We present such cases below. In what follows, we take the antecedent to c-command the reflexive (placed at its reflexivisation site: $\mathrm{T} / v$ ) from its case position ([spec, TP] for the nominative subject and [spec, $v \mathrm{P}]$ for the DAT OE).

\footnotetext{
${ }^{8}$ Therefore we prefer using the term antecedent to the term binder, as the latter one is typically understood in the CBT as a local antecedent to a reflexive form. The term antecedent is more neutral when discussing elements which locally ccommand maximally dependent forms spelled out as pronouns.
} 


\subsection{Index Raising}

Nikolaeva (2014) defines A(rgument) binding in a very conservative manner, as the sharing of the index between an antecedent and an anaphoric pronoun. Building on Chomsky (1986), Vikner (1985), Pica (1987, 1991), Hestvik (1992) and Avrutin (1994), she proposes that the ability to bind anaphors depends on the configuration of the DP antecedent and the pronoun/ anaphor, wherein pronouns and anaphors are indices that covertly raise to certain positions. As the diagram below shows, in her system, an Index first tucks in as an inner specifier of VP, and then optionally head moves first to $v$ and then to T:

(13) Index Positions - a ditransitive predicate (Nikolaeva 2014: 57)

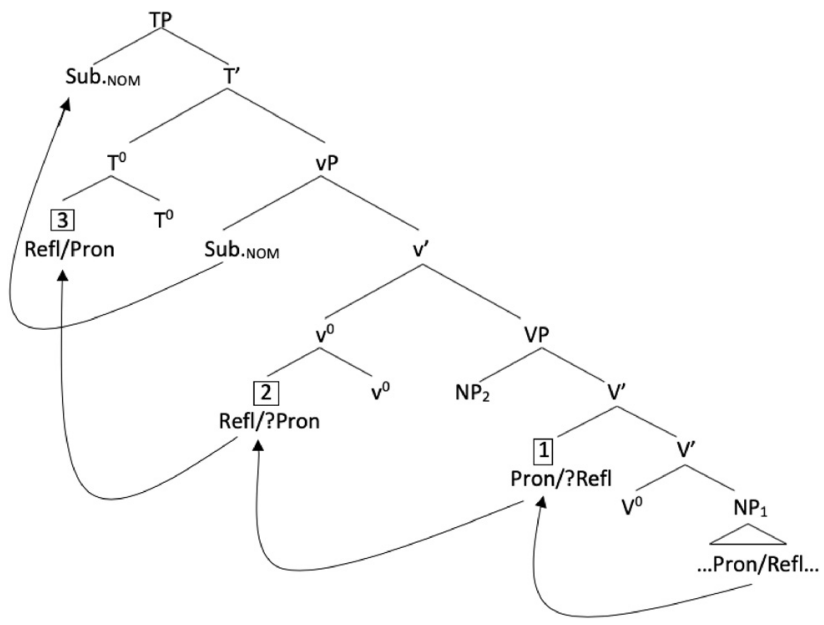

(14) Index Positions - a psychological predicate with DAT Experiencer

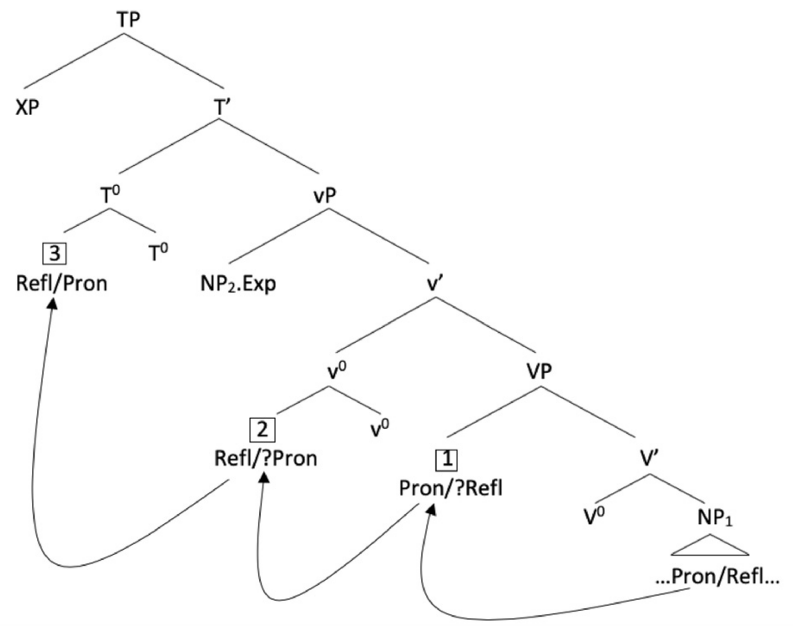

The diagrams in (13) and (14) show the placement of arguments in both the construction with ditransitive verbs and the one with psychological predicates. The direct object $\left(\mathrm{NP}_{1}\right)$ is the 
complement to $\mathrm{V}$, the indirect object $\left(\mathrm{NP}_{2}\right)$ occupies [spec, $\mathrm{VP}$ ], from which it c-commands $\mathrm{NP}_{1}$. The position of DAT OE in [spec, $v \mathrm{P}$ ] corresponds to the dative in (3-4) with psychological predicates. As the diagrams above show, Nikolaeva assumes two distinct positions for dative goals, benefactives and malefactives $\left(\mathrm{NP}_{2}\right.$ in [spec, VP]) and accusative/dative OEs ([spec, $\left.\left.v \mathrm{P}\right]\right)$. We share this view and follow Larson $(1988,1990,2014)$ for the placement of the benefactives and malefactives in [spec, VP] and Woolford (2006) for the placement of OEs in [spec, $v \mathrm{P}]$. Two positions are reserved for the agentive subject: the bottom of its $\mathrm{A}$-chain in $[\mathrm{spec}, v \mathrm{P}]$ and the top of its A-chain in [spec, TP]. As far as position XP is concerned, there are two possibilities, both compatible with our account. One is to say that it is a topic, either adjoined to TP or occupying a designated position in the left periphery (Rizzi 1997, 2014). ${ }^{9}$ The other is to say that it occupies a hybrid A/A' position, which is, however, not a case position for it, as proposed in Germain (2015) and Citko et al. (2018). ${ }^{10}$ Both assumptions recognise the standard claim that the position of [spec, TP] is reserved for the agreeing nominative subject (see Citko et al. 2018). The gist of Nikolaeva's system is as follows (Nikolaeva 2014: 68):

a. Movement: an Index (marked as Pron/Rfl in 14-15) must undergo covert Index Raising unless it is at a Reflexivization site or movement is no longer possible.

b. Reflexivization site: an Index is a sister to a node with label $\mathrm{D} / v / \mathrm{T}$ and is c-commanded by a specifier,

c. Co-argumental Reflexivization: if an Index is at a reflexivization site and is coindexed with a specifier which is its co-argument, the Index has to be realized as reflexive.

d. Reflexivization at spell-out: when the sentence is sent to spell-out, if an Index is coindexed with a specifier of the projection to which it is adjoined, the Index has to be realized as reflexive.

e. Pronominal is an elsewhere condition: if an Index has not been realized as reflexive, it is realized as pronominal.

\footnotetext{
${ }^{9}$ For instance, Ionin (2001) observes that preverbal arguments in neutral intonation SVO/OVS sentences are topics (topic being 'what the sentence is about'), either order can answer general questions of the 'what happened' type.

${ }^{10}$ Germain (2015) argues that feature transfer from the phase head to its complement head can be split (Split Feature Inheritance) and either both $\varphi$-features and the [+EPP] property are inherited by the complement head to the phase head or only the $\varphi$ - features are inherited and the transfer of the $[+\mathrm{EPP}]$ property is withheld. She analyses Russian constructions in which the $[+\mathrm{EPP}]$ property is not satisfied by nominative-marked DPs and concludes that in such cases, three (conflicting) properties should be taken into account. First, the fronted constituent does not reconstruct, which indicates that its landing site is an A-position, as observed in Bailyn (2004). Second, the OVS word order with the non-nominative argument in the initial position can facilitate a neutral wide-scope reading, which Germain takes to indicate the A-movement status of the object. Third, the non-nominative DP cannot function as an antecedent to reflexives from its landing site, which casts doubt on its A-position status. Germain proposes that these conflicting characteristics find a natural explanation if feature inheritance is split and the phase head C (Fin in her account where Rizzi's (1997) split CP architecture is assumed in (i)) passes on only $\varphi$-features to $\mathrm{T}$ but retains the $[+\mathrm{EPP}]$ property. Hence nominative case can be valued under Agree on the postverbal DP, while the non-nominative DP can move up to [spec, FinP] to satisfy the EPP-property.
}

(i) [ForceP Force [TopP Top [FocP Foc [FinP Fin]]]] (Russian Left Periphery, Germain 2015: 428)

In our representations we keep placing the dative-marked experiencer in the TP area without committing ourselves to either possibility. 
As VP is not a reflexivisation site by definition, the overt position of the Index (pronoun or anaphor) is mostly ignored in the calculation of its binding domain. ${ }^{11}$ The raising of the Index is decomposed into two distinct stages: pronominal raising (taking on a form of phrasal movement that creates a specifier position, position [1] in diagrams (13-14)) and Index raising proper (with the indexed raised via head movement to $v$, position [2], and next to T, position [3]). This decomposition resembles the view on head movement expressed in Matushansky (2006) but also ideas concerning celtic movement, see Sportiche (1996), Kayne (1985, 1991), Roberts (1992, 1993, 2009). The clause in (15e) clearly corresponds to the competition-based approach to binding, see (Safir 2004), and the movement-based approach, see (Hornstein 2001; Boeckx et al. 2008), where the pronoun is the default 'elsewhere' option wherever the reflexive cannot be licensed.

One of the consequences of the two stages of Index Raising is that the Index (in the form of the phrasal pronoun) can c-command other DPs in the clause from the specifier position it occupies (position [1]), whereas the Index moved via head movement and adjoined to $v / \mathrm{T}$ cannot c-command from the head adjoined position, as this would lead to undesirable Principle C violations (positions [2] and [3]). Nikolaeva (2014: 93-94) follows the definition of c-command in Hestvik (1992: 574): ' $\mathrm{x}$ c-commands $\mathrm{y}$ if every node dominating $\mathrm{x}$ includes $\mathrm{x}$ and $\mathrm{y}$, and $\mathrm{x}$ does not dominate $\mathrm{y}$ (where $\mathrm{x}$ includes $\mathrm{y}$ if $\mathrm{y}$ is dominated by every segment of $\mathrm{x}$, as proposed in May (1985).' Such a definition leaves the c-command domain of the adjunct undefined, as the node dominating the adjunct at the adjunction site does not include it. Alternatively, we can follow Citko et al. (2018) and invoke the Word Interpretation notion from Chomsky (1995: 322): 'at LF, $\mathrm{X}^{\mathrm{O}}$ is submitted to independent word interpretation processes WI, where WI ignores principles of the computational system within $\mathrm{X}^{\mathrm{o}}$.' If c-command from within a complex head (a word) leading to a violation of Binding Principle $C$ is such a 'principle of the computational system' then it can be ignored. ${ }^{12}$ This account rests on the assumption that there

\footnotetext{
${ }^{11}$ Exceptions include clause (15c) and co-argumental reflexivisation, where pronouns show not only strong anti-subject orientation but also anti-object orientation (i-ii).

(i) ${ }^{*}$ Mama $_{2}$ Pokazała Marii ${ }_{1} \quad \mathrm{ją}_{1 / 2} \quad$ (w lustrze). mother showed Mary.DAT her.ACC in mirror 'Mother showed Maria her (in mirror).'

(ii) ${ }^{*}$ Mama $_{2}$ Pokazała Marię̧ jej $_{1 / 2} \quad$ (w lustrze). mother showed Mary.ACC her.DAT in mirror 'Mother showed Maria to her (in mirror).'

An interesting finding regarding object binders in Double Object Constructions, as in (i-ii), was reported in an experimental study in Gogłoza et al. (forthcoming-a). Their results showed that binding of a pronoun by the higher object is significantly improved when that pronoun is emphasized by an adverbial sam 'alone'. The addition of sam may be thus considered as a repair strategy for reflexivization in Polish coargument contexts in which the binder is not merged in a reflexivization site $(v \mathrm{P} / \mathrm{TP})$. This idea is in line with Reuland (2011), who takes the combination of the pronoun and an emphatic element to be one of leading crosslinguistic strategies in forming lexical reflexives. This issue, however, remains beyond the scope of the current contribution (see Gogłoza et al. (forthcoming-a) for a detailed analysis couched in the Index Raising framework).

${ }^{12}$ Baker (1988) argues extensively that heads incorporated into other heads (where incorporation is a showcase example of head movement) cease to act upon elements they used to c-command before incorporation. So, head movement (incorporation) does not extend their c-domain, quite the contrary. For example, in Mohawk, the incorporated $\mathrm{N}$ no longer governs (under $\mathrm{c} / \mathrm{m}$-command) its possessor and does not license case on it, the verb as the incorporation host governs the possessor instead.
} 
is no overlap between the overt position of the reflexive/pronoun, the (covert) position relevant for establishing its c-domain and the position in which it is bound.

For the sake of demonstrating how Nikolaeva's system functions and what predictions it makes, consider (16) below, where the pronoun covertly raises to $\mathrm{T}$ past the dative experiencer in $[$ Spec, $v \mathrm{P}]$ :

a. Markowi $_{\mathrm{i}} \quad \dot{\mathrm{zal}}$ swojego $_{i} /$ jego $_{i}$ kolegi.

Mark.DAT (is) pity self s/his colleague.GEN

'Mark feels pity for his friend.'

b. [TP his $_{1}-\mathrm{T}\left[{ }_{v \mathrm{P}} \operatorname{Mark}_{1, \mathrm{DAT}}\right.$ self $_{1}-v$ [pity $\left[\left\{\operatorname{Index}_{1}\right\}[\right.$ friend $\left.\left.\left.\left.]\right]\right]\right]\right]$

The crucial empirical problem of (16) receives a natural explanation: the optionality between the pronominal and the reflexive possessive stems from the fact that the raising Index (yet unspelled as a pronoun or reflexive) can head move from its position [1] in (14) in VP to $v$ (position [2]) and then to $\mathrm{T}$ (position [3]) or remain adjoined to $v$ (position [2]). If the Index is adjoined to $v$, it is c-commanded by the coindexed dative experiencer and spelled out as the reflexive swó $j$ 'self s'. If it is raised further and adjoined to $\mathrm{T}$, it is spelled out as pronominal jego 'his', as it is now placed outside the c-domain of the coindexed dative experiencer.

Index Raising also explains the anti-subject orientation of pronouns and pronominal reflexives in a straightforward manner: the raising of the Index and its adjunction to $v$ or T places it in the c-domain of the subject, see (17b). Hence complementary distribution between anaphors and pronouns holds of the nominative subject, which is the closest potential antecedent for the Index covertly moved out of VP:

a. Tomek $_{\mathrm{i}}$ lubi swoich $_{\mathrm{i}}{ }^{*}$ jego $_{\mathrm{i}}$ kolegów.

Tomek.NOM likes.3sG self/his friends.ACC

'Tomek likes his colleagues.'

b. [TP Tomek self $_{\mathbf{1}}$ 's/ $^{*}{ }^{\text {his }} \mathbf{1}_{\mathbf{1}}-\mathrm{T}\left[{ }_{v \mathrm{P}}\right.$ Telf self $_{\mathbf{1}}$ 's $^{*}{ }^{*} \mathbf{h i s}_{\mathbf{1}}-\boldsymbol{v}$ [ likes [\{Index $\}[$ friends $\left.\left.\left.\left.]\right]\right]\right]\right]$ (modelled on Nikolaeva 2014: 63)

Index Raising, as represented in (13-14), also implies that there is considerable discrepancy between the overt and the covert binding domains of the object NPs: the anaphor or pronoun placed in the c-domain of the object in overt syntax (position [1] in (13)) is moved outside it to positions [2] or [3] in covert syntax. Thus, both the object's impossibility to function as antecedent to an anaphoric reflexive and its legitimate coindexation with pronominal possessives (lack of Condition B effect) in (1) receive a natural account.

\subsection{Modifying the theoretical framework}

Nikolaeva's account of binding briefly outlined above raises at least three questions in the context of the minimalist architecture of grammar. (a) How crucial is the role of the GB-style referential indices? Can we perhaps preserve the empirical adequacy of this account in an indexfree theory? (b) What is the rationale behind the D-bound/Index raising? (c) Why exactly does it move via particular positions indicated in the diagrams in (13) and (14) above? 
First, let us replace the traditional notion of binding as index sharing, advanced by Nikolaeva, with the assumption that anaphoric binding is not a specific operation of grammar but a result of derivational processes which are independently necessary. Rather than insisting on index-sharing, involving a considerable amount of look-ahead, we follow Hicks (2009) and subscribe to the view that LF-relevant Binding is based on Agree for the feature [var:_] (variable), interpretable and valued on R-expressions and pronouns ([var: $\mathrm{x}]$ ) and unvalued on anaphors (D-bound/Index): ${ }^{13}$
a. name
var: $[+$ int, +val]
b. pronoun var: $[+\mathrm{int},+\mathrm{val}]$
c. reflexive var: $[+$ int, - val $]$

Hicks insists that binding relations require the sharing of $\varphi$-features between the antecedent and the dependent but they are not limited only to sharing these features ('What is at stake in anaphor binding is referential dependency, not simply a $\varphi$-feature dependency.' Hicks 2009: 112). So for Hicks indexically dependent elements show the following structure and they have their own interpretable and valued $\varphi$-features:

$$
\left[\mathrm{DP}\left[\mathrm{D}[\varphi]\left[\mathrm{var}_{-}\right] \mathrm{him}\right][\mathrm{NP} \text { self }]\right]
$$

We adopt the structure in (19) for English and take the syntactic object in (19) to be equivalent to the D-bound of Safir (2014) and the Index of Nikolaeva (2014). Feature [var:_] acts as a probe. It cannot find any matching goal in its c-domain, so it probes upwards within the immediate derivational phase, in line with Rezac (2004), Béjar and Rezac (2009) and Zeijlstra (2012). We adopt the following definition of upward Agree, modelled upon Zeijlstra (2012: 17): ${ }^{14}$

(20) Upward Agree: $\alpha$ can Agree with $\beta$ iff:

a. $\alpha$ carries at least one unvalued feature and $\beta$ carries a matching valued feature;

b. $\beta$ c-commands $\alpha$;

c. $\beta$ is the closest goal to $\alpha$.

In the concrete English example below upward Agree operates in the following context:

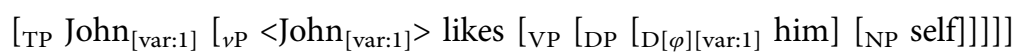

\footnotetext{
${ }^{13}$ Limits of this publication do not allow us to refer in detail to other recent minimalist theories of anaphoric binding, such as Kayne (2002), Zwart (2002), Hasegawa (2005), Heinat (2006), Boeckx, et al. (2008), Reuland (2011), Antonenko (2012) or Zubkov (2018).

${ }^{14}$ Zeijlstra's original definition uses the term uninterpretable, rather than unvalued, as he basically follows Chomsky (2000, 2001, 2008), where uninterpretable features are unvalued, while we are more sympathetic to the classification of syntactic features in Pesetsky and Torrego (2004, 2007) and Hicks (2009), where valuation and interpretability are kept distinct. Zeijlstra (2012) advocates the idea that upward Agree is the only canonical mode for Agree, while Rezac (2004) and Béjar and Rezac (2009) argue that in principle Agree should be allowed to operate in both modes ('flipping' Agree): the downward one is the default but the upward one switches on when the probe cannot find an appropriate matching goal within its c-domain.
} 
In (21) the unvalued feature [var:_] serves as a probe, searches upwards for a matching goal with a valued [var:x] feature and finds it in the DP John in [spec, $v \mathrm{P}$ ]. Thus a minimalist relation of Agree for [var:x] replaces index sharing of the GB vintage. ${ }^{15}$ We propose that the Polish reflexive pronoun and reflexive possessives have the following representations (in the diagrams, the ' 0 ' in $\mathrm{D}$ indicates that in contrast to English (19), no part of the lexical reflexive corresponds to D itself).
a. $\left[\mathrm{DP}\left[[\varphi]\left[\mathrm{var}_{-}\right]\right.\right.$
D] [NP siebie] $]$ Self c.
b. [NP $\left[\mathrm{DP}\left[[\varphi]\left[\mathrm{var}_{-}\right] \mathrm{D}\right]\right.$ [NP swój$\left.\left.]\right]\left[\mathrm{NP}^{\mathrm{dom}}\right]\right]$ d. self's house
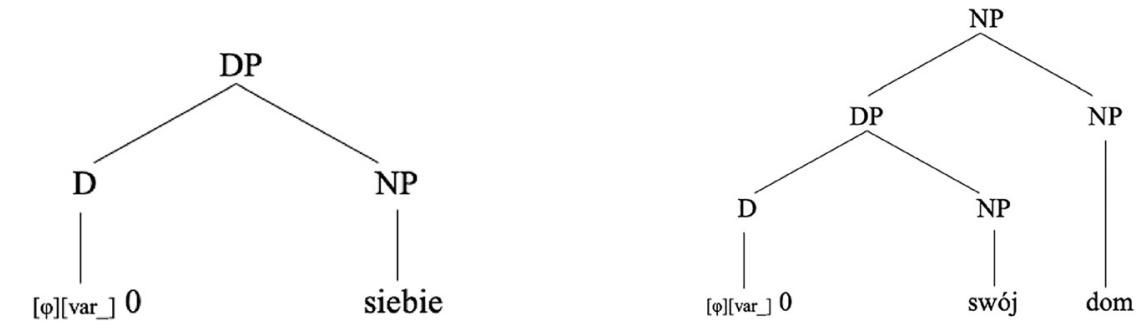

Second, we submit that the D-bound/Index in Polish shares an important property with the clitic/weak pronoun: they both leave the VP and move into the functional domain of the clause. We find an overt equivalent to Nikolaeva's Index Raising in the distribution of the clitic/weak pronoun and its climbing out of the domain of the infinitive. In Polish, domains for both Abinding and clitic/weak pronoun (hence CL/WP) distribution overlap (up to the application of the Tensed Sentence Condition, Chomsky (1981)):

a. $\operatorname{Jan}_{1}$

$\left(\mathbf{g o}_{2}\right)$

kazał $\left(\right.$ go $\left._{2}\right) \mathrm{Marii}_{3}\left[\mathrm{PRO}_{3}\right.$ Jan.NOM him.CL.ACC told Maria.DAT

( $\left.\mathbf{g o}_{2}\right)$ pokazać $\mathbf{g o}_{2}$ w lustrze $\left.{ }^{\star} \mathbf{g o}_{2}\right]$ 'Jan told Maria to show him in the mirror.'

$\underline{\mathrm{CL} / \mathrm{WP}}$

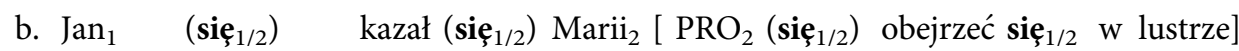
Jan.NOM REFL.CL.ACC told Maria.DAT watch.INF in mirror 'Jan told Maria to show him in the mirror.'

$\underline{\text { SELF }}$

(24) Maria $_{1}$ kazała Piotrowi 2 [PRO ${ }^{2}$ pozdrowić swoich ${ }_{1,2}$ przyjaciół]. Maria.NOM told Piotr.DAT greet.INF selfs friends 'Maria told Piotr to greet his/her friends.'

\footnotetext{
${ }^{15}$ We follow the idea that binding is Agree for [var:_], rather than Agree for [ $\varphi$ ] (Reuland 2011). It allows us to abstract away from problematic aspects of the correlation between structural case and binding (the binder/bindee as a nonstructural case bearer ((3)-(5), object binder, etc.). Reuland's proposal straightforwardly covers only constructions in which both the binder and the bindee bear structural case and it does not easily lend itself to applications where either the binder or the bindee bear inherent/quirky case.
} 
In (23a) the clitic/weak pronoun in Polish can occupy a variety of positions in the clause but the right-most one must be right-adjacent to the lexical verb, see Witkoś (1998). We take this position to be $v$. The clitic/weak pronoun cannot be lexicalised within VP, the lexical projection of the verb. It can climb out of the infinitive into the main clause; in the process, it typically occupies positions corresponding to $v$ or $\mathrm{T}$. The clitic form of the reflexive pronoun shows the same distribution pattern in (23b). (24) shows that the same domain allows for long distance binding, where the reflexive can be bound either locally, by object-controlled PRO or nonlocally, by the main clause subject. ${ }^{16}$

On a more technical note, clitic/weak pronouns are impoverished in their sets of $\varphi$-features: only the [number] and [gender] features are both interpretable and valued in them but not the [person] feature, which is interpretable but unvalued (see Franks 2017 and Stegovec 2016 for an analysis of clitics/weak pronouns along these lines):

$$
\begin{aligned}
& \text { clitic/weak pronoun: gender }[+\mathrm{int},+\mathrm{val}] \\
& \text { number }[+ \text { int, }+ \text { val }] \\
& \text { person }[+ \text { int, }- \text { val }]
\end{aligned}
$$

This fact has a tangible consequence for the placement of the clitic/weak pronoun: it cannot express its $\varphi$-features in situ and moves to a position of $v$ (and T) where the valuation of the [person] feature takes place, in line with upward Agree and the following principle (Béjar \& Rezac 2003: 53; Franks forthcoming-a: 5): ${ }^{17}$

(26) Person as Probe: an interpretable person feature must be licensed by entering into an Agree relation with a functional category.

These authors assume that the head $v$ is equipped with the $[-$ int, + val $]$ person feature and some form of the [+EPP], either as an independent property or a sub-feature of the [person] feature, as in Pesetsky and Torrego (2001), to generate displacement. The clitic/weak pronoun moves to this head position to become $\varphi$-complete. Its further movement to $\mathrm{T}$ and onwards to a higher clause receives an account equivalent to clitic climbing. We submit that our D-bound/Index follows a similar derivational path, but unlike the clitic/weak pronoun, it carries no valued phi-features at all. Its $\varphi$-feature valuation 'piggy-backs' on the valuation of the [var:_] feature; indexically dependent elements end up carrying $\varphi$-features of their antecedents. This produces the effect of antecedent-

\footnotetext{
${ }^{16}$ The analogy between Index raising and clitic movement is forcefully argued for in Hestvik (1992), who analyses differences between English and Norwegian and points out that Norwegian pronouns show anti-subject orientation in the sense that they do not mind being bound by a c-commanding object but they cannot be bound by the subject.

${ }^{17}$ The idea that the clitic is impoverished in terms of its $\varphi$-feature composition and must move to a functional head is applied to account for particular order of clitics within the clitic cluster in Slavic, the Person Case Constraint: In a combination of clitic pronouns, the last one has to be $3^{\text {rd }}$ person (Franks 2017).

In their analysis of the Person Case Constraint (PCC), Béjar and Rezac (2003: 53) propose the Person Licensing Constraint (PLC) axiom: An interpretable 1st/2nd person feature must be licensed by entering into and Agree relation with a functional category. The PLC, as well as the idea that the [person] feature is a separate probe from the [number] feature, implies that 1st/2nd person clitics appear at the head of the cluster.
} 
agreement highlighted by Safir (2014). But before this happens, the D-bound/Index shows the following features in its VP-internal position:

$$
\begin{aligned}
\text { D-bound/Index: } \varphi \text {-features: } & \text { gender }[+ \text { int, }- \text { val }] \\
& \text { number }[+ \text { int, }- \text { val }] \\
& \text { person }[+ \text { int, }- \text { val }]
\end{aligned}
$$

We assume that in constructions with the D-bound/Index, the relevant functional category from definition (26), namely $v$, carries an unvalued person feature ([-int,-val]) which is nevertheless equipped with the $[+\mathrm{EPP}]$ property. ${ }^{18}$ Thus, crucially, it attracts the D-bound/ Index just like it does clitics/weak pronouns. Analogously, the head $\left[_{[\varphi]\left[\mathrm{var}_{-}\right]} \mathrm{D}\right]$ of the D-bound/ Index is able to move further to $v / \mathrm{T}$ within the domain determined by the Tensed S-Condition of Chomsky (1981) according to the scenario sketched out in Roberts (2009), where clitic climbing involves attraction/sharing of $\varphi$-features (all or just the [person] feature) between the D-head and the $v /$ T heads. ${ }^{19}$

In our analysis of binding thus far the similarity between the $\left[_{[\varphi]\left[\mathrm{var}_{-}\right]} \mathrm{D}\right]$ head and the clitic/weak pronoun was crucial: they share the deficiency in the [person] feature licensing. Yet, there is one respect in which they are obviously different from each other. Franks (2017, forthcoming-a) postulates that clitic/weak pronoun are deficient in three dimensions: the semantic one, the structural one and the phonological one. The last one distinguishes the $\left[_{[\varphi]\left[v_{-}\right]} \mathrm{D}\right]$ head from the clitic/weak pronoun. In (28) below, the D head of [DP $\left[{ }_{[\varphi]\left[\mathrm{var}_{-}\right]} \mathrm{D}\right][\mathrm{NP} \mathrm{D}$-bound] $]$ moves from its thematic/case position to the head $v(\mathrm{~T})$ where its underspecified person feature is compensated for, but it is not phonologically impoverished the way clitics are. This is why its movement forms a chain in which the copy is pronounced (see the positions of się 'se' in (23b) vs. siebie/swój 'self, self's' in (24)); the valuation of the [var_] feature and the deletion of $\varphi$-features recoverable form the antecedent NP in [spec, $v \mathrm{P} / \mathrm{TP}$ ] is a signal for the copy to be pronounced as a reflexive/reflexive possessive. Lack of such a local licensing is a signal for the copy to be pronounced as a pronoun/pronominal possessive. In fact, the reflexive clitic in (23b) fully shares properties of both the clitic/weak pronoun and the $\left[_{[\varphi]\left[v_{-} r_{-}\right]} D\right]$ head; it is a perfect overt movement analogue to $\left[[\varphi]\left[\mathrm{var}_{-}\right] \mathrm{D}\right]$.

Below we present a step by step derivation of a simple example:

\footnotetext{
${ }^{18}$ Pesetsky and Torrego $(2004,2007)$ allow for Agree (and movement relations) involving probes/goals sharing unvalued features which later obtain a value at a further stage of the derivation. The unvalued [person] feature on $v$ later receives the value of the [person] feature of the antecedent to the D-bound/Index.

${ }^{19} \mathrm{~A}$ reviewer notes that since [ [phi][var:1] $\left.\mathrm{D}\right]$ moves via head movement and adjoins to $v$, it does not c-command its trace in the base position, which indicates that the binding dependency is established at LF indirectly. We concur with the reviewer's suggestion that in this case, it may be that binding holds between the antecedent and the trace of the $\mathrm{D}^{0}$ in the base position while the $\mathrm{D}^{0}$ head's variable feature in the $v$-adjoined position, which is valued under upward Agree with the antecedent's variable feature, only mediates this relation.
} 
(28) a. $\operatorname{Jan}_{1}$ zobaczył siebie $_{1} / *$ jego $_{1}$.

Jan saw self $/{ }^{\star h i m}$

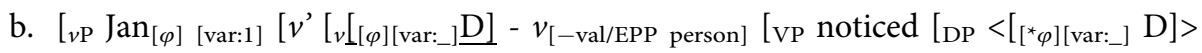
[NP Index]]

Narrow Syntax (NS)/PF relevant $\varphi$-feature expression: the [(_val) person] element of the functional head $v$ Agrees for and attracts the [(_val) person] element of the $\varphi$-feature set on the part of the head $\left[{ }_{\left[{ }^{*} \varphi\right][\text { var: } 1]} \mathrm{D}\right]$ and triggers its raising to $v$ (and optionally further to $\mathrm{T}$, in line with the clitic raising possibility).

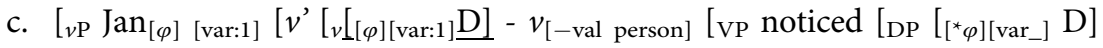
[NP Index]]]]

NS/LF relevant binding: the unvalued [var:_] feature of D probes upwards and finds a matching goal in the NP Jan, merged in [spec, vP]. The [var:_] feature valuation produces an LF relevant binding dependency. ${ }^{19}$

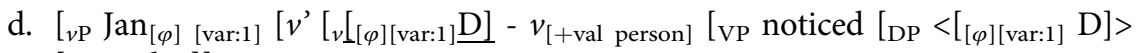
[NP Index]]

NS/PF relevant valuation of $\varphi$-features on $\left[_{[\varphi][\text { var:1] }} \mathrm{D}\right]$ by the $\varphi$-features of the antecedent NP (under phase-internal c-command) because $\varphi$-feature valuation 'piggy backs' on Agree for [var:1].

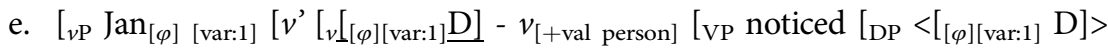
[NP siebie/self]]

PF-relevant Spell-Out of the copy of $\left[_{[\varphi][\text { var:1] }} \mathrm{D}\right]$ at the bottom of the chain: [DP

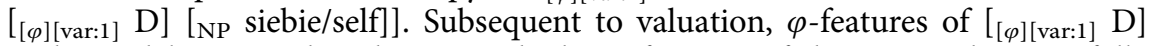
undergo deletion under identity with the $\varphi$-features of the NP as they are fully recoverable from them, as postulated in Reuland (2011). ${ }^{20}$ The bottom of the chain of the D-bound/Index spells out as siebie 'self, a form morphologically devoid of any person, number and gender distinctions in Polish. ${ }^{21}$

Our account predicts that the difference between languages where the object can function as an antecedent to a reflexive pronoun depends on whether or not the reflexive element can remain in situ to express its $\varphi$-features. So we assume that the D-bound/Index in English can express these features in situ, without any compensatory movement to $v /$ T. This implies that there is no mismatch between the position where the LF-relevant antecedent/bindee relation is

\footnotetext{
${ }^{20}$ As deletion operations apply at the end of each cycle determined by phase-based Spell-Out (Chomsky 1995, 2000, 2001, 2008 , 2013), we take $\varphi$-feature deletion on $\left[[\varphi]\left[\mathrm{var}_{-}\right] \mathrm{D}\right]$ to apply after the clitic climbing operations it participates in.

${ }^{21} \mathrm{~A}$ similar idea of an element raising (to the edge of the $v \mathrm{P}$ Phase) and having its copy pronounced as reflexive is applied in an analysis of binding in German in Safir (2004) and in Lee-Schoenfeld (2008: 291). According to the latter source the licensing of sich 'self' co-indexed with Mutter requires covert movement:
}

(i) Die Mutter ${ }_{i}$ lässt $\left[{ }_{v \mathrm{P}}\right.$ die Kleine $\mathrm{jich}_{\mathrm{?}_{\mathrm{i} / \mathrm{j}}} / \mathrm{ihh}_{\mathrm{i} /{ }^{*} \mathrm{j}}$ die Schokolade in den Mund stecken]. the mother lets the little_one self/her the chocolate in the mouth to_stick

'The mother lets the little girl stick the chocolate in her mouth.' 
established and the PF realisation of this relation on the bindee. In English the bindee (Dbound/Index) remains in the same position in the LF and PF representations, in the c-domain of the superior object. As we have proposed above, there is such a mismatch in Polish, where the clitic-like nature of the bindee (D-bound/Index) carries it to a position outside VP for its PF realisation. $^{22}$

In the frame of his multi-attachment hypothesis, Franks (forthcoming-b: 149-150) proposes a more profound parametric difference with respect to strategies of binding between languages like English and Bulgarian (whose core reflexive element sebe is similar to Polish siebie 'self'). Both involve movement and the parametric distinction relevant for subject orientation of binding stems from the composition of the reflexive phrase. He assumes the following two general structures for such reflexive phrases:
a. [XP $[$ the man] ... [DP1 [D1 him] [ReflP [Refl self] [DP2 the man]]]]
b. $\left[{ }_{v \mathrm{P}}\left[{ }_{v}\right.\right.$ sebe- $\left.-v\right] \ldots\left[{ }_{\mathrm{KP}}\right.$ sebe $\left[{ }_{\mathrm{AgrP}}(\mathrm{si})[\mathrm{DP} \mathrm{D}[\right.$ ReflP $[$ Refl sebe $\left.\left.]]]\right]\right]$

The key element in the analysis is the reflexive element Refl, treated as a syntactic head and projecting its own phrase embedded within a larger nominal constituent. In (29a), corresponding to English, Relf is transitive and has a $\mathrm{DP}_{2}$ complement, which becomes its antecedent.

\footnotetext{
${ }^{22}$ There is an area of Polish grammar where a bindee behaves in the English-like manner. Reciprocal constructions in Polish have properties markedly distinct from reflexives and identical to Russian reciprocals (Willim 1989; ReindersMachowska 1991; see Rappaport 1986 for Russian). For instance, in contrast to reflexives, reciprocals are not subject oriented and can be bound by the object as well:
}

(i) Policjanci $_{1} \quad$ wypytywali ich $2 \quad$ o siebie $_{1,2}$, /jednego o drugiego . $_{2}$.

Policemen.NOM questioned them.ACC about self /each_other.LOC

'The policemen ${ }_{i}$ questioned them ${ }_{j}$ about each other $\mathrm{r}_{\mathrm{i} / \mathrm{j}}$.

Reciprocals cannot be bound across a closer potential antecedent, such as a nominal possessor in [spec, NP] or the PRO subject of the infinitive:
(ii) Pisarze $_{1}$ czytali wspomnienia $\quad$ o $\quad$ sobie $_{1}$. writers.NOM read reminiscences.ACC about self.LOC
'Writers read reminiscences about each other.'
(iii) ${ }^{*}$ Pisarze $_{1} \quad$ czytali $\quad$ [wspomnienia $\quad$ Tołstoja $\quad$ o $\quad$ sobie $_{1}$ ]. writers.NOM read reminiscences.ACC Tolstoj.GEN about self.LOC
'Writers read the reminiscences of Tolstoj about each other.'
(iv) Chłopcy $_{1}$ czytali dziewcząt 2 wspomnienia o boys read of_girls memories about self
'The boys read the girls' memories about themselves/them.'
(v) $\mathrm{My}_{1}$
kazaliśmy $\mathrm{im}_{2}$
$\left[\mathrm{PRO}_{2}\right.$ nalać
sobie ${ }^{*} 1 / 2 /$ jeden drugiemu ${ }^{*} 1 / 2$ herbaty]
we $_{\mathrm{NOM}}$ asked them.ACC to_pour
self /each_other.DAT tea.ACC
'We ${ }_{1}$ asked them ${ }_{2} \mathrm{PRO}_{2}$ to pour each other" ${ }^{*}{ }_{1 / 2}$ tea.

In the terms of our analysis of reflexives presented here, the reciprocal pronouns in Polish can express their $\varphi$-features in situ and do not undergo clitic-like movement to $v /$ T. Hence the lack of subject-orientation and long-distance binding effects. 
The derivation of the English reflexive construction is based on movement and stems from the analyses in Kayne (2002), Hornstein (2001) and Boeckx, et al. (2008). As movement needs to meet locality conditions, the antecedent the man can move to the nearest argument position, which may be the position of the superior object.

In (29b), showing Bulgarian, but also applicable to Polish, the head Refl is intransitive and has no DP complement. It pursues an alternative reflexivisation strategy and moves by itself, associates with $v$ and ultimately gives rise to a subject-orientated reflexive predicate. This part is similar to our analysis. However, in the context of binding by DAT OEs in (3b), we take our proposal to be more comprehensive, as Franks concentrates only on elements which are indexically dependent and reflexive at Spell-Out, while we address indexically dependent elements which are spelled out as both reflexive and pronominal.

Furthermore, Nikolaeva's proposal for Index Raising (IR), as well as the review of the data above raise at least one conceptual question concerning the precise trajectory of IR: the status of position [1] in (13-14). It must have properties of an A-type position, namely a position in which the Index can act as a binder. Evidence that this is so comes from Anti-Cataphora Effects (ACE):

$$
\begin{array}{ll}
{ }^{\star} \operatorname{Jan}_{1} & \text { pokazał }\left[\mathrm{jej}_{2} \text { dyplom] } \quad\right. \text { [koleżance } \\
\text { Jan.NOM showed her diploma.ACC friend.DAT } & \text { Maria.GEN } \\
\text { 'Jan showed her diploma to Marta's friend.' }
\end{array}
$$

(30) shows that R-expressions in Polish cannot be placed in positions following co-indexed pronouns, even if these pronouns do not apparently c-command them in an obvious manner. The grammar of Polish (as well as other Slavic languages) does not tolerate cataphoric relations.

Nikolaeva (2014) takes the ACE in (30) to be a clear consequence of the movement of the possessive pronoun from within the containing NP to a c-commanding position (the tucking in as a separate specifier of V, position [1] in (13)-(14)). From this position, the Index triggers a Condition $\mathrm{C}$ violation with respect to Maria.

However, apart from its role in causing ACE, the A-status of position [1] does not stand on a firm ground: it is neither a thematic nor a case position for the possessive pronominal, as its base position within NP probably provides for both properties. ${ }^{23}$ Therefore, although it is clear how important a function position [1] holds in Nikolaeva's (2014) system, it is dubious on conceptual grounds even in theories that allow for more liberal movement into A-positions. ${ }^{24}$ Thus, we turn to another hypothesis which provides for the relevant c-command without recourse to position [1] in (13-14). Despić (2011, $2013,2015)$ develops an account of binding in Serbo-Croatian (SC) which relies to a large degree on the idea that adjectival possessives are adjuncts and therefore c-command outside the NP they are part of. In Serbo-Croatian, the possessive c-commands from its adjoined position, on a theory of adjunction as in Kayne (1994), and thus causes a Principle B effect, (cf. 32) and a Principle C effect (cf. 32b), which does not occur in English examples, e.g. (31). Significantly, Polish shares with SC the fact that

\footnotetext{
${ }^{23} \mathrm{We}$ find little evidence for the movement of the D-bound/Index as XP in the verbal/clausal domain discussed here. However, phrasal movement is attested in binding into the nominal domain, an issue that remains beyond the scope of this contribution.

${ }^{24}$ In addition, as mentioned by an anonymous reviewer, movement to position [1] violates anti-locality (Abels 2003) which is a ban on movement that is too short and does not bring the moving element any closer to its ultimate goal. In minimalist terms, such movement is rendered superfluous and must be blocked.
} 
possessive pronouns trigger Anti-Cataphora effects (33a), although nominal possessives do not, see (33b), as discussed in Witkoś et al. (forthcoming):

(31) a. His $\mathrm{i}_{\mathrm{i}}$ latest movie really disappointed Kusturica $\mathrm{i}_{\mathrm{i}}$

b. Kusturica, 's latest movie really disappointed him $_{\mathrm{i}}$.

(32) a. ${ }^{*}$ Njegovi $_{\mathrm{i}}$ najnovij $j_{\mathrm{i}}$ film je zaista razočarao Kusturicu $\mathrm{i}_{\mathrm{i}}$ his latest movie is really disappointed Kusturica

b. ${ }^{\star}$ Kusturicin $_{\mathrm{i}}$ najnovij $_{\mathrm{i}}$ film $\mathrm{ga}_{\mathrm{i}}$ je zaista razočarao. Kusturica's latest movie him is really disappointed

a. ${ }^{\star} \operatorname{Jego}_{\mathrm{i}}$ siostra bardzo pocieszyła Janka $\mathrm{i}_{\mathrm{i}}$. his sister.NOM very comfort.PAST Janek.ACC 'His sister comforted John very much.'

b. Siostra Janka $\mathrm{J}_{\mathrm{i}}$ bardzo $\mathrm{go}_{\mathrm{i}}$ pocieszyła. sister.NOM Janek.GEN very him.ACC comfort.PAST 'Janek's sister comforted him very much.'

These authors conclude that Polish seems to employ two structures to represent nominals with possessives: the simpler bare NP-structure is used with pronominal and reflexive possessives, while the more complex structure involving Possessive Phrase and another functional projection on top of it (FP) is used with nominal possessives:
a. [NP jego [NP siostra]]
his.GEN sister.NOM
'his sister'
b. [FP [NP siostra] [F [PossP [NP Janka] [ Poss [NP

$$
\text { sister.NOM Janek.GEN }
$$ 'Janek's sister'

Nominals with pronominal possessors appear to be smaller, truncated versions of structures with nominal possessors. ${ }^{25}$ The result is that only the pronominal possessives are expected to c-command outside the NP they modify, while nominal possessives do not. Significantly, the structure in (34a) has the following advantage: the pronominal c-commands outside its NP from its base position, the position where it has both its thematic role and case licensed, thus it's A-position. In consequence, we can do away with the movement to position [1], argued for in Nikolaeva's framework, and assume that IR is a head movement targeting positions [2] and [3].

\footnotetext{
${ }^{25}$ In his analysis of English possessive constructions Despić (2015) proposes a similar solution in that the pronominal possessor is placed at a lower level of the DP structure than the nominal possessor or the reciprocal possessor:
}

(i) $\left[{ }_{D P}\right.$ Mary/each other [D' [D 's] [PossP my/their/her [Poss' Poss [NP friends] $\left.\left.\left.]\right]\right]\right]$ 
Considering our discussion thus far and our modifications and updates of Nikolaeva's original proposal, the Lexicalisation Rule reads as follows:

(35) The Lexicalisation Rule:

The (bottom copy in the chain of the) D-bound/Index contributes to its lexicalisation as reflexive when (i) $\left[_{[\varphi]\left[\text { var_}_{-}\right]} \mathrm{D}\right]$ is adjoined to $v /$ T and (ii) the [var:_] feature of the $\left[{ }_{[\varphi]\left[v_{-}\right]} \mathrm{D}\right]$ is involved in Agree with the [var:x] feature of the NP in [spec, $\left.v \mathrm{P} / \mathrm{TP}\right]$. The antecedent must occupy its case position. Otherwise the D-bound/Index is lexicalised as a pronoun. $^{26}$

\section{THE SYSTEM AT WORK}

We now proceed to demonstrate the derivational details of our account. The crucial properties of the derivation stem from the probing procedures in which two features of the $\left.\left[{ }_{[\varphi][} \mathrm{var}_{-}\right] \mathrm{D}\right]$ head are involved: the [var_] feature probing for a c-commanding goal (an NP/DP with a valued [var: $1 / 2$, etc.] feature and the unvalued $\varphi$-features. The [person] feature from this set matches and is attracted by the [_val person] feature on a functional head, $v / T$. This Agree and feature sharing relation forces movement of the $\left[_{[\varphi]\left[\mathrm{var}_{-}\right]} \mathrm{D}\right]$ head to $v$. While the valuation of the [var:_] feature is relevant for the LF-interpretation of the D-bound/Index, the Agree and feature sharing of the [person] feature, the movement of the $\left[_{[\varphi]\left[\mathrm{var}_{-}\right]} \mathrm{D}\right]$ head to $v / \mathrm{T}$ (and its further cliticclimbing style movement) is relevant for the PF-interpretation of the D-bound/Index: it facilitates its lexicalisation at Spell-Out.

\subsection{A-binding as Agree \& Move (or Move \& Agree)}

Let us start with constructions involving a ditransitive verb in a simple clause:

$$
\begin{array}{llll}
\text { Maria }_{1} \text { pokazała Piotrowi } & {\left[\left[\text { swoje }_{1, *_{2}} / \mathrm{jego}_{2} / \mathrm{jej}_{*}\right]\right.} & \text { zdjęcie }] \\
\text { Maria.NOM showed Piotr.DAT self s/his/her } & \text { picture } \\
\text { 'Maria showed Piotr her/his picture.' } &
\end{array}
$$

Two available derivations of (36) depend on the order between probing by the [var:_] feature and the Agree and movement driven by the [_val, person] feature sharing between $\mathrm{v}$ and the $\varphi$-feature complex of $\left[_{[\varphi]\left[\mathrm{var}_{-}\right]} \mathrm{D}\right]$. If the latter applies first, $\left[_{[\varphi]\left[\mathrm{var}_{-}\right]} \mathrm{D}\right]$ is moved out of VP and adjoined to $v$. Probing for the [var:_] feature from this position finds the subject Maria as the goal, [var:_] receives value 1 and the lexicalisation Rule in (35) returns a reflexive form:

\footnotetext{
${ }^{26} \mathrm{We}$ still keep the distinction between co-argument reflexivisation and non-co-argument reflexivisation, Nikolaeva's (18d).
} 


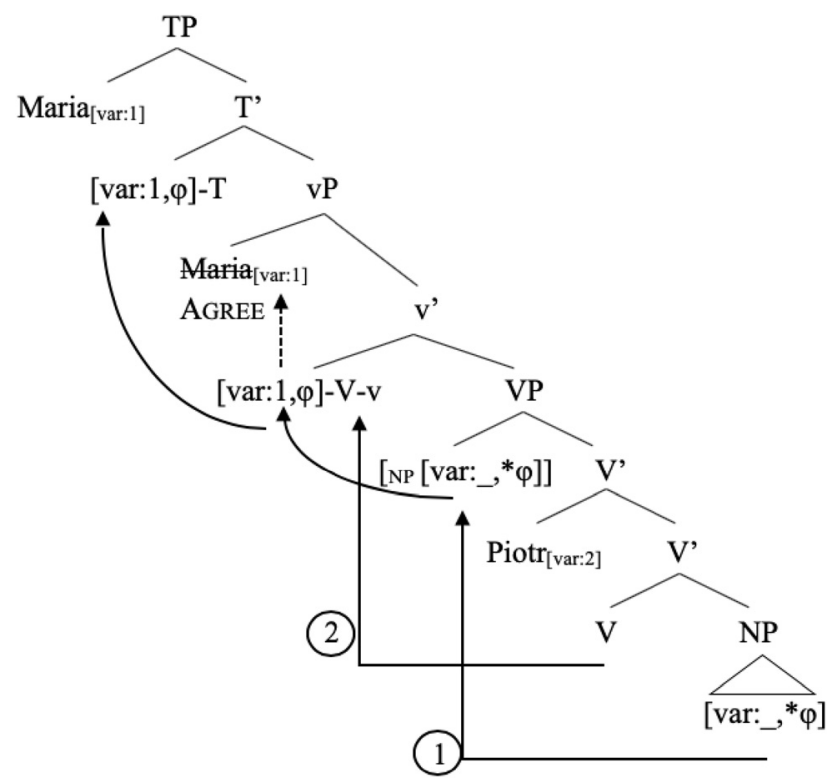

In recognition of broadly conceived minimality considerations, ${ }^{27}$ we assume that this nonlocal relation by-passing NP Piotr [var:2] $_{\text {in }}$ possible for at least two reasons. One possibility is to invoke a covert equivalent to scrambling. This is step one in this derivation, which raises the lower object NP to the outer specifier position of $\mathrm{V}$. This movement is to be expected in a language allowing for frequent post- and preverbal scrambling of object arguments (see Grewendorf \& Sabel 1999 for an analysis of German or Tajsner 2008; Witkoś 2008; and Wiland 2016) for an analysis of overt scrambling in Polish). As a result, $\left[_{N P}\left[{ }_{[\varphi]\left[v_{-}\right]} D\right]\right]$ is equidistant from $v$ to the same degree as the other object. Thus $v$ [-val, person] can access $\left[_{[\varphi]\left[v_{-}\right]} \mathrm{D}\right]$ as the

${ }^{27}$ Movement relations respect Relativised Minimality in (A) and Agree and Move obey the Minimal Link Condition in (B).

(A) Relativised Minimality (Roberts 1993: 32)

In the configuration (i), $\mathrm{X}$ antecedent-governs $\mathrm{Z}$ only if there is no $\mathrm{W}$ such that:

(i) ...X. . [Y $\ldots$.....Z]

(ii) $\mathrm{W}$ is a typical potential antecedent-governor for $\mathrm{Z}$;

(iii) $\mathrm{W}$ intervenes between $\mathrm{X}$ and $\mathrm{Z}$.

(B) Minimal Link Condition (Chomsky 1995: 311, 356)

(i) $\mathrm{K}$ attracts $\alpha$ only if there is no $\beta, \beta$ closer to $\mathrm{K}$ than $\alpha$, such that $\mathrm{K}$ attracts $\beta$.

(ii) $\beta$ is closer to $K$ than $\alpha$ unless $\beta$ is in the same minimal domain as (a) $K$ or (b) $\alpha$. 
most relevant part of the NP and cause it to adjoin to it, having its [_val person] feature valued in the process. Next, the [var:_] feature of $\left[_{[\varphi]\left[\mathrm{var}_{-}\right]} \mathrm{D}\right]$ probes upwards and ends up bound to the subject. The second possibility is to rely on the Principle of Minimal Compliance (Richards 1997, 1998; Landau 2000), bearing in mind the upward probing nature of [var:_]. ${ }^{28}$ The gist of the PMC is that an initial legitimate local relation involving a particular head (probe) in domain $\mathrm{D}$ 'pays the derivational tax' and opens the way to a less local relation which would otherwise violate a constraint on minimality or locality in the same domain D. In the concrete case of (37) the more local V-to- $v$ movement opens up the possibility for the less local movement of [ $[\varphi]\left[\mathrm{var}_{-}\right]$ $\mathrm{D}]$ to $v$. Both movements apply to the same domain of $v \mathrm{P}$. The delay in the valuation of the [var:_] feature here reflects the generally accepted idea that satisfaction of Binding Principle A need not apply immediately but at different stages of the derivation (Belletti \& Rizzi 1988; Lebeaux 2009).

If the order of operations in (37) is the reverse, that is, the [var:_] feature searches for its value from the base position of $\left[{ }_{[\varphi]\left[v_{-} r_{-}\right]} D\right]$, it encounters the superior object Piotr as goal and the feature receives value [var: 2]. Next, the [-val, person] feature of the $\varphi$-feature set is involved in Agree and feature sharing with the relevant [_val, person] probe on $v$ and moves to adjoin to it. The lexicalisation Rule in (35) returns a pronominal form at Spell-Out:

\footnotetext{
${ }^{28}$ Richards $(1997,1998)$ shows that in a number of cases a grammatical principle is observed once in a particular structure and then ignored by further operations applying to the same domain. For instance, in Bulgarian multiple wh-movement observes superiority but once the most superior wh-phrase has moved, the other ones can do so at will, e.g. kakavo 'what' cannot cross kogo in (iii) but it can do so in (iv), when koj 'who' has moved to C first:
}

(i) $\quad *\left[w_{2}-C \ldots w_{1} \ldots t_{2}\right]$

(ii) $\quad\left[w_{1}-w_{3}-w h_{2}-C \ldots t_{1} \ldots t_{2} \ldots t_{3}\right]$

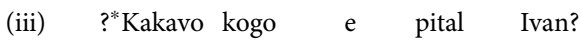

what whom AUX asked Ivan

'What did Ivan ask whom?'

(iv) Koj kakavo kogo e pital?

who what whom AUx asked

'Who asked whom what?'

Landau (2000: 70-71) discusses cases of subject control (across the object, as in: John promised Mary to do the dishes) in the following configuration:

(v) $\quad\left[\mathrm{T}_{1} \ldots \mathrm{DP}_{1} \ldots v_{1} \ldots \mathrm{DP}_{2}\left[\mathrm{CP} \mathrm{T}-\mathrm{Agr}_{1}\left[\mathrm{TP} \mathrm{PRO}_{1} \ldots ..\right]\right]\right]$

For Subject Control to hold here, $\mathrm{T}_{1}$ must access the complex T-Agr ${ }_{1}$ across another potential probe $v_{1}$. The PMC allows for this, as $\mathrm{T}_{1}$ is first involved in a legitimate local Agree with $\mathrm{DP}_{1}$. Once this relation is executed $\mathrm{T}_{1}$ becomes involved in a less local minimality-violating relation with $\mathrm{T}-\mathrm{Agr}_{1}$, across $v_{1}$. This relation would be impossible on its own, without the first local relation. 


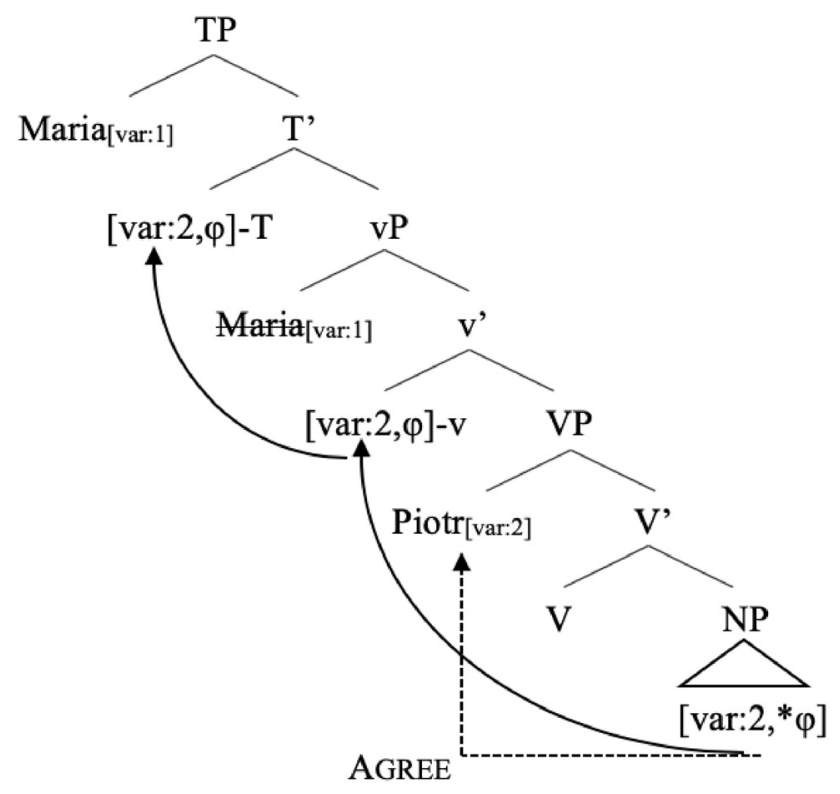

We assume that $\left[_{[\varphi]\left[\mathrm{var}_{-}\right]} \mathrm{D}\right]$ still remains an active element of the derivation on the assumption of Chomsky (2001) and Pesetsky and Torrego (2001) that features which have been valued remain visible until a given derivational phase (here $v \mathrm{P})$ is completed. Furthermore, the relation between $v$ [_val, person] and [ $\left.[\varphi]\left[\mathrm{var}_{-}\right] \mathrm{D}\right]$ is also allowed for by the PMC applied to the combination of operations Agree and Move. The more local relation of the [var:_] feature valuation, and subsequent $\varphi$-feature valuation between $\left[_{[\varphi]\left[\text { var }_{-}\right]} \mathrm{D}\right]$ and the superior object within VP embedded in the $v \mathrm{P}$ phase, opens up the way for the less local relation involving $v$ and $\left.{ }_{[\varphi]\left[\mathrm{var}_{-}\right]} \mathrm{D}\right]$. Following its movement to $v,\left[_{[\varphi]\left[\mathrm{var}_{-}\right]} \mathrm{D}\right]$ must be lexicalised as a pronominal, as expected.

The full menu of options involving interactions between both valuation procedures shows in the relatively complex cases, known as long distance binding. In the context of an infinitive clause (exemplifying Object Control) the antecedent for the D-bound/Index is either the more local PRO or the more remote subject of the main clause. Significantly, the D-bound/Index can be lexicalised as either a reflexive possessive or a pronominal possessive for both indexical dependencies. Example (39b) has a QP main clause subject to show that accidental co-reference is excluded and only LF-relevant binding is at stake here: 
(39) a. Maria ${ }_{1}$ kazała Piotrowi 2 pozdrowić swoich $_{1,2} / \mathrm{jego}_{2} / \mathrm{jej}_{1}$ przyjaciół. Maria.NOM told Piotr.DAT greet.INF self $s /$ his/her friends 'Maria told Piotr to greet his/her friends.'

b. Każda studentka kazała Piotrowi $\mathrm{i}_{2}$ pozdrowić swoich $_{1,2} / \mathrm{jego}_{2} / \mathrm{jej}_{1}$ przyjaciół. every student.PL.F.NOM told Piotr.DAT greet.INF self s/his/her friends 'Every (female) student told Piotr to greet his/her friends.'

As our first approximation, we follow the approach to analogous cases in English in Hicks (2009:158):

(40) a. John 1 wondered [which pictures of himself ${ }_{1 / 2 / 3}$ ] Bill 2 claimed Paul $_{3}$ had bought.

b. $\mathrm{John}_{1}$ wondered [CP $_{\mathrm{DP}}$ which pictures of himself $\left.{ }_{1 / 2 / 3}\right]$ Bill $_{2}$ claimed $\left[_{\mathrm{CP}}<\left[_{\mathrm{DP}}\right.\right.$ which pictures of himself $\left.{ }_{1 / 2 / 3}\right]>\mathrm{Paul}_{3}$ had bought $<$ [DP which pictures of himself $\left.{ }_{1 / 2 / 3}\right]>$

Hicks assumes that the ambiguity of binding in the English case of (40) stems from the interplay between the copy theory of movement and probing for the [var:_] feature on the part of the reflexive, shown in (40b). Crucially, he allows for a certain derivational lag in the valuation of this feature, so either [var:_] starts probing early in the derivation and probes from its original position receiving interpretation marked as [val:3] here, or it probes later, after the constituent including himself $f_{\text {[var_: }}$ has been moved in the derivation to tend to the needs of the $w h$-feature. The latter valuation tactics bears fruit in the form of interpretations marked as [var:2] or [var:3]. Thus the wh-feature drives movement, while the [var:_] feature drives the setting up of an indexical dependency and either feature can be satisfied first. This overall view of satisfaction of Binding Principle A is reminiscent of the notion that Principle A is liberal and can be satisfied at any point in the derivation (Belletti \& Rizzi 1988; Lebeaux 2009).

We apply this strategy to the Polish example in (39) above relying on the intuition that the movement of $\left[{ }_{[\varphi]\left[v_{-}\right]} \mathrm{D}\right]$ to $v /$ T motivated by [-val, person] feature sharing or valuation of its [var:_] feature could take place first. The sharing of the [-val, person] $/ \varphi$-features between $v / T$ and $\left[{ }_{[\varphi]\left[v_{-}\right]} D\right]$ drives movement, the way the $w h$-feature does in (40) above. Its multiple landing positions (consider the positions for go 'him' and się REFL in (23)) account for the lexicalisation options in infinitives, as the movement of the head $\left[_{[\varphi]\left[\mathrm{var}_{-}\right]} \mathrm{D}\right]$ can stop either within the embedded infinitive or continue to the main clause $v$ and $\mathrm{T}$ with either value. In terms of landing sites and movement options the head $\left[_{[\varphi]\left[\mathrm{var}_{-}\right]} \mathrm{D}\right]$ corresponds to clitics/weak pronouns.

First, we present the structure relevant for interpretation [var:2, $\varphi$ ], where the controller of PRO, Piotr 2 , is the ultimate antecedent but it achieves its objective through $\mathrm{PRO}_{2}$. In this derivation Agree between $\mathrm{PRO}_{2}$ and [var_] on the D-bound/Index takes place first and next the [_val, person] feature in the $\varphi$-set of the D-bound/Index forces its movement to $v / \mathrm{T}$ in the embedded clause, driven by the [-val, person] feature on this head. As a result, the D-bound/Index is lexicalised as a reflexive, in line with the Lexicalisation Rule in (35): 
(41)

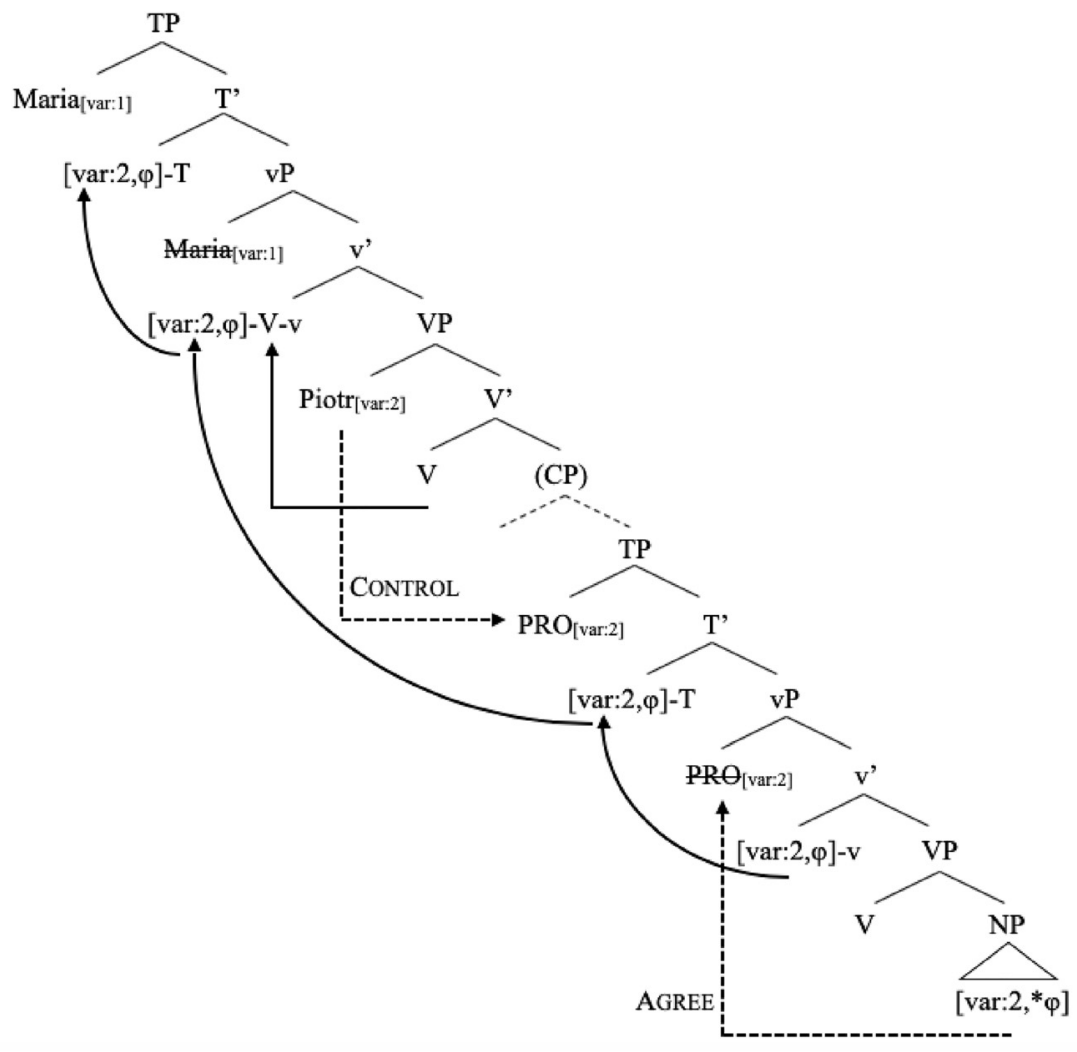

In the second scenario the order of operations is the same. First the [var_] feature is valued against $\mathrm{PRO}_{[\text {var:2] }}$ and next the Agree for the [_val, person] feature in the $\varphi$-feature set triggered by the [_val, person] feature of $v /$ T forces movement of [ $\left.{ }_{[\varphi]\left[v_{-}\right]} \mathrm{D}\right]$, but here $\left[_{[\varphi]\left[\mathrm{var}_{-}\right]} \mathrm{D}\right]$ clitic-climbs to the main clause. Our concerns for RM and MLC-compatibility cause us to rely on the PMC strategy again: we propose that a local V-to- $v$ movement in the main clause $v \mathrm{P}$ phase opens the way for the less local climbing of $\left[{ }_{[\varphi]\left[v_{-}\right]} D\right]$ to the main clause $v$. As a result, the LF-interpretation of the anaphoric relation is identical to that in (41) but the lexicalisation is different, as the $\left[_{[\varphi]\left[v_{-}\right]} \mathrm{D}\right]$ head is not locally c-commanded by the goal sharing the value for the [var_] feature, in line with (35):

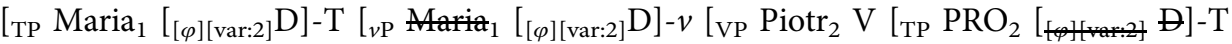

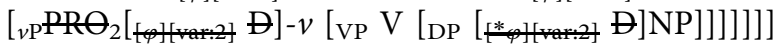

Another scenario represents the interpretation [var:1, $\varphi$ ], in which Maria $_{[\text {var:1] }}$ is the antecedent. In this case movement to the main clause $v / T$ driven by Agree for the [_val, person] feature in the $\varphi$-set of $\left[{ }_{[\varphi]\left[v_{-}\right]} D\right]$ takes place first, its way paved by the V-to- $v$ movement in the main clause crucial from the point of view of the PMC. Once the head $\left[_{[\varphi]\left[\mathrm{var}_{-}\right]} \mathrm{D}\right]$ finds itself there, its [var:_] feature probes upwards to reach the nearest legitimate c-commanding goal and obtains value [2] for this feature. Thus the LF-relevant relation is set up between the main clause 
subject and the D-bound/Index. The Lexicalisation Rule in (35) forces the appearance of the reflexive form at Spell-Out, as $\left[_{[\varphi]\left[\text { var_}_{-}\right]} \mathrm{D}\right]$ adjoined to matrix $v / \mathrm{T}$ is locally c-commanded by the NP valuing the [var:_] of the D head.

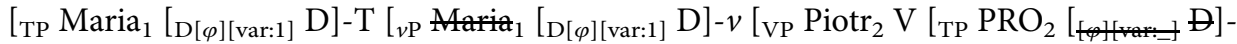

$$
\begin{aligned}
& \left.\left.\left.\mathrm{T}\left[{ }_{\nu \mathrm{P}} \mathrm{PR}_{2}[\mathrm{O}]-v\left[{ }_{\mathrm{VP}} \mathrm{V}\left[{ }_{\mathrm{DP}}\left[{ }_{1} \mathrm{O}\right] \mathrm{NP}\right]\right]\right]\right]\right]\right]
\end{aligned}
$$

We are now left with the last of the four interpretive options available for (39): the main clause subject functions as the antecedent for the pronominal possessive. This interpretation requires an impossible combination of conditions within our system: on the one hand the very local relation Agree valuing the [var:_] feature on $\left[{ }_{[\varphi]\left[\mathrm{var}_{-}\right]} \mathrm{D}\right]$ requires that the upward Agree be

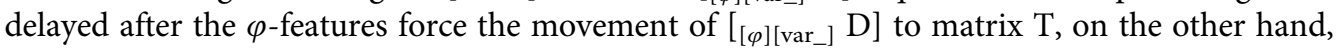
such movement predicts that the only available lexicalisation form of the D-bound/Index should be reflexive. We are facing an impossible dilemma indeed:

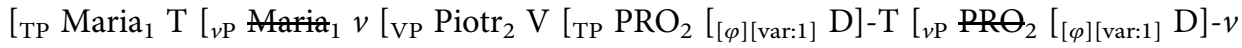

$$
\begin{aligned}
& \text { [VP V[DP [_: } \mathrm{O}] \mathrm{NP}]]]]]]]
\end{aligned}
$$

The contradictory requirements of the LF- and PF-licensing of the referentially dependent form in (44) can be solved if looking at the $\left[{ }_{[\varphi]\left[v_{-}\right]} \mathrm{D}\right]$ adjoined to embedded T we fall back on the PMC again, as the domain of the $v \mathrm{P}$ phase in the main clause contains not only a local head movement relation (V-to- $v$ movement) that opens the possibility that a longer one can proceed unobstructed in its wake, but also a local Agree relation. This domain includes a relation of object control, shown in (41), which implies local Agree, once the Agree Theory of Control in Landau (2000, 2008) is assumed. This local Agree-based relation of control opens up the way for the less local relation of Agree for the [var:_] feature reaching across $\mathrm{PRO}_{[\text {var:2] }}$ and $\operatorname{Piotr}_{[\mathrm{var}: 2]}$, accessing Maria ${ }_{[\mathrm{var}: 1]}$ in [spec, $\left.v \mathrm{P}\right]$.

\subsection{Head Movement and Index Raising}

The type of movement that we propose for both clitic-climbing and the D-bound/Index is head movement. There are two basic empirical reasons for this claim on our part. ${ }^{29}$ The first one pertains to the locality constraints on these movements: the domains of clitic climbing and A-binding overlap within the tensed sentence, neither can reach out of it. As Willim (1989), Tajsner (1990) and Witkoś (1993) show, Polish tensed clauses are relatively opaque to extraction of phrasal elements via A' movement with the exception of extraction out of subjunctives clauses selected by chcieć 'want'. These clauses are quite transparent to phrasal wh-movement. However, they are not transparent to either clitic climbing by a personal pronoun clitic (46), reflexive clitic (47) or binding domain extension (48):

Którą książkę chcesz [żeby [studenci czytali $t$ samodzielnie?]] which book want.2SG so_that students read.3PL.PAST independently 'Which book would you like the students to read independently?'

*Jan go chce [żeby [studenci pozdrawiali]]
Jan him wants so_that students greeted
Intended: 'John would like the students to greet him.'

${ }^{29}$ We are grateful to a reviewer for advising us on relevant aspects of the issue of head-movement for our analysis. 
*Jan się chce [żeby [studenci golili $t$ co rano]] Jan REFL wants so_that students shave every morning Intended: 'John would like the students to shave every morning.'

(48) $\operatorname{Jan}_{1}$ chce [żeby [studenci ${ }_{2}$ patrzyli na siebie ${ }_{* 1 / 2}$ ]] Jan wants so_that students looked at self 'Jan wants the students to look at themselves/each other/him.'

If both clitic-climbing and D-bound/Index raising constituted a subtype of phrasal A'movement, they should be extractable from $\dot{z} e b y$-complement clauses. Infinitives, on the other hand, are transparent domains to all types of movement in Polish, including the most demanding one in the form of head-movement. Taking clitic-climbing and reflexive-raising as reflexes of head movement has a long-line ancestry in linguistic research, cf. Hestvik (1992), Avrutin (1994), Safir (2004), Nikolaeva (2014), Franks (2017, forthcoming-b), etc. For lack of space we cannot discuss the view expressed in Cardinaletti and Starke (1994) that clitics/weak pronouns have the status of phrases.

The other reason for forsaking phrasal movement as a vehicle for domain-extension with binding has to do with unwelcome Condition C effects. Consider (36) again. If the D-bound/ Index were to move as a phrasal element (a pronoun) to [spec, $v \mathrm{P} / \mathrm{TP}$ ] it should c-command the coindexed proper name placed in [spec, VP] and plausibly trigger a Condition C effect. But this does not take place at all. If the movement in question is head movement, then according to Hestvik (1992) and Citko et al. (2018) the D-bound/Index does not c-command the proper name from within the complex head.

However, assuming that $\left[_{[\varphi]\left[v_{-}\right]} D\right]$ moves via head movement begs at least two questions, as pointed out by a reviewer: the issue of improper movement, i.e. a movement of the head out of a maximal projection that has previously undergone movement itself, and excorporation, necessary for the climbing out of the infinitive into the main clause. We address these issues in turn and show that both are plausible operations within the current version of minimalism.

First, the alleged improper movement of the type we envisage is already tacitly present and endorsed in Chomsky (1986: 174-175):

(49) They told us that [[pictures of each other] would be on sale]

(50) They told us about each other (themselves)

Chomsky proposes to capture the configuration where the subject functions as the binder in (49-50) via the following partial representation, supposed to capture the essence of both examples:

they $a_{\mathrm{i}}$-INFL [vp tell us about $\mathrm{e}_{\mathrm{i}}$ ]

For $a$ to reach the Infl (Agr) head node in the main clause it must quite clearly move out of the maximal projection it is a sub-constituent of. But clearly a is moved out of the embedded subject in (49) and, on current analyses, the embedded subject itself has been previously moved into its position via A-movement from [spec, $v \mathrm{P}$ ]. So $\alpha$ is moved via head-movement from within a phrasal domain that has been moved. Incidentally, a fruitful line of research into problems connected with Relativised Minimality and the MLC stems from the notion of 'smuggling' (Collins 2005a,b), whereby a larger constituent is moved first and next a smaller one 
is extracted from within it. In (49) the A-movement of the subject 'smuggles' a to a position from which it moves to the matrix $\mathrm{T}$.

Ever since head movement appeared on the research agenda in the standard GB framework (Travis 1984; Baker 1985, 1988; Chomsky 1986) the issue of nonlocal head movement has been treated with a considerable dose of suspicion. In the standard accounts such as Baker's, where the Head Movement Constraint (ECP) was derived from the Empty Category Principle (Chomsky 1981, 1982), non-local head movement was claimed to lead to serious ECP violations:

$$
{ }^{*}\left[\mathrm{XP} \mathrm{Z}^{0}+\mathrm{X}^{0}\left[\mathrm{YP} \mathrm{Y}^{0}[\mathrm{ZP} \mathrm{t}]\right]\right]
$$

The trace of the head $\mathrm{X}^{0}$ was not properly governed (antecedent-governed), as the c-commanding $\mathrm{Y}^{0}$ intervenes. In this theory head $\mathrm{Z}^{0}$ was able to reach $\mathrm{X}^{0}$ but only as a part of a complex head $\left[\mathrm{Y}^{0}+\mathrm{Y}^{0}\right.$ ], formed via successive-cyclic head movement. So for example it predicted that it is impossible to move a perfective auxiliary straight to $\mathrm{C}^{0}$ over and above, or through $\mathrm{Infl}^{0}$, where subsequently the dummy do was inserted (Roberts 1991:212):

${ }^{\star}$ Have John does gone?

The relevant structure is as follows: have John [t'-s] tgone; $t$ is the base position of the aux, $t^{\prime}$ is where aux illicitly transits through Infl. Yet, data from clitic climbing in Italian point in the opposite direction; the clitic (a head) moves through a position of its local verb in the infinitival complement and adjoins to the inflected verb in the main clause:

(54) La volevo $t^{\prime}$ chiamare $t$ ieri.

her I.wanted to-call yesterday

'Yesterday I wanted to call her up.'

The intermediate phrase shows that the clitic pronoun transits through the embedded nonfinite Infl. The issue of excorporation can receive two alternative treatments compatible with our account of A-binding outlined above.

If the standard distinction between heads and head movement and phrases and phrasal movement is maintained, we could turn to the Relativised Minimality-based proposal in Roberts (1991, 1993). Roberts proposes to distinguish between two types of head movement: morphologically subcategorised head movement (typical of formation of morphologically inflected verbs) and unselected head movement (typical of pronominal clitic placement). He thus relativises head intervention further than Chomsky (1986). Roberts shows that the HMC and the ECP block movement only in the former case but not the latter. In the case of subcategorization, the projection of the host head contains a sub-zero level to which the moved head becomes a sister (55a). In the case of head-to-head adjunction, the relation between the host head and moved head is looser, (55b) (Roberts 1991:214):
a. $\left[\mathrm{XP}\left[\mathrm{X}\left[\mathrm{X}^{-1}\right]\left[\mathrm{Y}^{0}\right]\right]\left[\mathrm{YP}_{\mathrm{Y}} \mathrm{t}_{\mathrm{Y}}\right]\right.$
b. $\left[\mathrm{XP}\left[\mathrm{XO} 0\left[\mathrm{X}^{0}\right]\left[\mathrm{Y}^{0}\right]\right]\left[\mathrm{YP}_{\mathrm{Y}}\right]\right]$

In terms of the definition of the ECP in note (46) $\mathrm{X}^{-1}$ counts as an intervening governor, as it c-commands $\mathrm{Y}^{0}$. However, the situation is quite different in $(55 \mathrm{~b})$; here the $\mathrm{X}^{0}$ head is adjoined to and its lower segment does not c-command $\mathrm{Y}^{0}$ on its own, on the standard 
assumption that only entire categories c-command, while their segments do not (Chomsky 1986). So, technically, the two-segment $X^{0}$ does not constitute an intervener for a further movement of $\mathrm{Y}^{0}$. This is how Roberts accounts for clitic-climbing in Italian in (54). Now, our account of A-binding is based on the parallel between clitic/weak pronoun placement (including the so-called clitic climbing). Thus our head $\left[_{[\varphi]\left[\mathrm{var}_{-}\right]} \mathrm{D}\right]$ moves via head-to-head adjunction and meets locality constraints in the form of both the GB-specific ECP or the more general Relativised Minimality (the would-be $\mathrm{X}^{0}$ intervener is only a segment and it does not c-command and intervene).

Second, let us consider the movement of $\left[_{[\varphi]\left[v_{-}\right]} D\right]$ in the context of the Bare Phrase Structure of Chomsky (1995), where distinctions based on bar levels have been abandoned in favour of relational notions such as [+/-minimal; +/-maximal]. The clitic is both an $\mathrm{X}^{0}$ and an $\mathrm{XP}$, it is [+minimal; +maximal] and the status of head movement becomes unclear. Assuming that the target of movement projects, both the moved head and the maximal projection are $[+$ maximal $]$ at the landing site. Many authors then allow heads to move into positions shared at target with maximal projections, namely the specifier position, e.g. Bosković (2002), Matushansky (2006), Landau (2006)Vicente (2007) or Franks (2017). In some cases, mostly connected with verb movement and the composition of complex inflected heads, the movement of one head into the specifier of the next one not only brings them into a configuration of linear adjacency but is also followed by morphological merger (Matushansky 2006), forming a constituent on the PF-branch of grammar. This step is, however, not required in all cases, as argued in Vicente $(2007)^{30}$. Importantly, we assume that this step is not required in 'non-subcategorised' head movement in terms of the distinction made in Roberts (1991, 1993). What we take to be 'non-subcategorised' movement here is movement driven by the [+EPP] property or the [_val pers] feature on $\mathrm{v} / \mathrm{T}$. This implies that as long as the the $\left[_{[\varphi]\left[\mathrm{var}_{-}\right]} \mathrm{D}\right] \mathrm{X}^{0} / \mathrm{XP}$ does not reach its final position it can keep on moving from [spec, $v \mathrm{P}$ ] to [spec, TP] in structures like (41), provided MLC and RM considerations are met (and the PMC plays a vital role here, as indicated in our discussion). It merges with the head at the final landing site. So, technically speaking, excorporation is not an issue any more, because we are dealing with a successive cyclic movement targeting specifiers.

${ }^{30}$ Vicente (2007: 25-26) discusses the notion of the complex head (such as an inflected verb created through repeated head movement and adjunction) in the context of Chomsky's (1995) Bare Phrase Structure. He adopts the following definition of the word, following Julien (2002: 321):

(i) A word is a sequence of morphemes with internal cohesion and distribution.

This definition admits that words need not be constituents (though in most cases they are). In the following example from Chichewa the tense and agreement prefixes do not form a unit (a constituent) with the verbal stem and the applicative and perfective suffixes (which jointly form a complex head on their own). Yet, the entire complex is a word, as no lexical material intervenes between the $[[[-u m b]-i r]-a]$ complex head and the prefixes occupying their base positions in their respective separate projections:

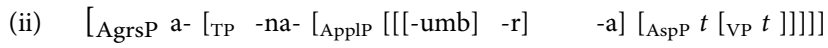

SM -PST -mold - APPL $\quad$-PERF

'(he) molded'

This structure is an indication that on the strength of the definition in (i) się REFL and a pronominal clitic/weak pronoun can be said to form PF-relevant words with the following/preceding heads without PF-merger. 
For the sake of concreteness, we follow the ideas expressed in Bosković (2002), Vicente (2007) and Landau (2006). With Bosković (2002: 334) and Franks (2017: 157-158) we assume that clitics are $\mathrm{X} / \mathrm{XPs}$ that do not branch and the only position they can occupy is either the complement position or the specifier position in the VP. Significantly, they cannot occupy head positions, as then they would have to project and branch to allow for complements in the sister position, so whenever they look like occupying a head position (e.g. clitic auxiliaries) they in fact occupy a specifier position of a head that is silent and they agree with it in the relevant features. Thus (56c) with a silent projecting head $\alpha$ is the structure preferred to (56d), with $X^{0} / X P$ in the head position:
a. $\left[\mathrm{VP} \mathrm{V}\left[\mathrm{X}^{0} / \mathrm{XP}\right]\right]$
b. $\left[\mathrm{vP}\left[\mathrm{X}^{0} / \mathrm{XP}\right][\mathrm{v}, \mathrm{V}\right.$ YP] $]$
c. $\left[{ }_{a P}\left[\mathrm{X}^{0} / \mathrm{XP}\right]\left[\alpha^{\prime}, 0 \alpha \mathrm{YP}\right]\right]$
d. ${ }^{*}\left[\mathrm{XP}\left[\mathrm{X},\left[\mathrm{X}^{0} / \mathrm{XP}\right] \mathrm{YP}\right]\right]$

We heavily rely on a close empirical parallel between the scope of overt climbing of the reflexive clitic sie REFL in (23)-(34) and the scope of A-binding, crediting them to a common source. This implies that we need to introduce a technical alteration to our structure in (22), so that it should become more compatible with what Bosković (2002) proposes for clitic pronouns and clitic auxiliaries. While się REFL can be treated as a self-standing clitic ( $\left.\mathrm{X}^{0} / \mathrm{XP}\right)$ in (56a), the

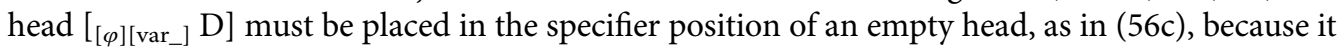
cannot project and branch:

$$
\text { [DP }\left[[\varphi]\left[\text { var_ }_{-} \mathrm{D}\right]\left[0_{\mathrm{D}}[\mathrm{NP} \ldots]\right]\right]
$$

With Vicente (2007) and Landau (2006), we assume that the $\mathrm{X}^{0} / \mathrm{XP}$ can move via the path accessible to XPs. Hence from the structure in (57) the $\left[_{[\varphi]\left[v_{-}\right]}\right.$D] clitic head moves out into $[\mathrm{spec}, v \mathrm{P}]$ and/or [spec, TP], each time tucking in under the primary specifier position filled with the subject argument or DAT OE:

$$
\left[{ }_{v \mathrm{P}} \mathrm{DP}_{\mathrm{SUB}} /{ }_{\mathrm{DAT}} \mathrm{OE}\left[{ }^{\prime}{ }_{[\varphi \rho]\left[\mathrm{var}_{-}\right]} \mathrm{D}\right]\left[{ }_{v}, v\left[\mathrm{vP}\left(\mathrm{DP}_{\mathrm{IO}}\right)\left[\mathrm{v}^{\prime} \mathrm{V}\left[{ }_{\mathrm{DP}}\left[{ }_{[\varphi]\left[\mathrm{var}_{-}\right]} \mathrm{D}\right]\left[0_{\mathrm{D}}[\mathrm{NP} \ldots]\right]\right]\right]\right]\right]\right.
$$

This movement meets the empirical requirements placed on both clitic-climbing and Abinding domain extension if we make a conservative assumption that an $\mathrm{X}^{0} / \mathrm{XP}$ constituent must meet locality conditions which are jointly common to both head movement and phrasal movement. This implies that movement out of the bare infinitive is fine, while movement out of the tensed domain may be acceptable for certain phrases but not for heads. Thus $\mathrm{X}^{0} / \mathrm{XP}$ will not move out of the finite clause and its movement is regulated by such conditions as the MLC and the PMC.

The structure in (57) and the movement of $\left[_{[\varphi][\text { var_ }]} \mathrm{D}\right]$ also provides a clue as to why the reflexive element is pronounced at the bottom of the chain. Let us assume that a phrasal structure larger than a head can be lexicalised as a word (Vicente 2007; Starke 2002 and Caha 2009), and that the entire phrase in (57) is lexicalised as siebie 'self or swój 'selfs'. Then if a subconstituent of this larger structure is (copied and) moved away, it is still the larger structure including the copy of the moved sub-constituent that is spelled out rather than the sub-extracted 
part $\left[_{[\varphi]\left[v_{\text {var }}\right]} \mathrm{D}\right] .{ }^{31}$ The sub-extracted part only receives, at its landing site, an instruction as to whether its source constituent in (57) is lexicalised as reflexive or not.

Finally, let us turn to the notion of anti-cataphora effects and Condition C. If we make the plausible assumption that only the entire nominal constituent, and not its sub-constituents, count as proper antecedents/triggers for Binding Conditions A, B and C, then we account for the fact that $\left[_{[\varphi]\left[\text { var }_{-}\right]} \mathrm{D}\right]$ in (5) can trigger Condition $\mathrm{C}$ effects only from the position it visibly occupies, while $\left[_{[\varphi]\left[v_{-}\right]} D\right]$, moved away to the vicinity of a c-commanding head (its tucked-in specifier) cannot. Entire categories count as antecedents, while their subparts do not (although $\left[_{[\varphi]\left[v_{2} r_{-}\right]} D\right]$ technically c-commands the proper name from the specifier position).

In sum, the adoption of a BPS-compatible picture of the structure and derivation introduces non-trivial changes to the notion of head movement, instrumental when dealing with cliticclimbing or any operation similar to it (our D-bound/Index raising). The $\mathrm{X}^{0} / \mathrm{XP}$ element $[+$ minimal $/+$ maximal $]$ is a double-faced syntactic item. It moves driven by the [-val pers] feature, targets the $[\mathrm{spec}, v \mathrm{P} / \mathrm{TP}]$ position as any other XP would, tucks in under the primary specifier and ultimately merges with the adjacent head at its ultimate landing site. Yet, its headlike nature does not allow it to cross the tensed CP boundary. The copy pronunciation at the bottom of the chain is forced by the idea that a word-like lexicalisation is assigned to the entire constituent in (57), rather than its sub-parts.

\subsection{A-binding and phases}

So far we have avoided the issue of phase boundaries and the Phase Impenetrability Condition (PIC), for instance in the context of the movement of $\left[_{[\varphi]\left[\mathrm{var}_{-}\right]} \mathrm{D}\right]$ from the T-adjoined position in the infinitive to the $v$ head in the main clause or upward Agree from this position reaching the main clause subject in [spec, $v \mathrm{P}]$. As for constraints on these relations imposed by the $v \mathrm{P}$ and $\mathrm{CP}_{\text {inf }}$ phases, it is plausible that these projections do not function as (strong) phases here in the original sense of Chomsky $(2000,2001)$. The case of the impenetrability of the $v \mathrm{P}$ projection in our derivations is less problematic. The embedded $v \mathrm{P}$ functions as a phase for the Agree relation between the embedded object (or its possessor) and the main clause subject only if the [var:_] probe acts from its bottom-most position inside the VP. If we, however, retain the idea that this probing can be withheld until the head $\left[_{[\varphi]\left[\mathrm{var}_{-}\right]} \mathrm{D}\right]$ is raised to $v$ for the valuation of the [-val person] feature, $v \mathrm{P}$ is no longer a phase for an element placed at its edge, as the head belongs to the edge.

The case of the intervening CP projection of the infinitive is not fatal either and a number of options present themselves. For instance, Landau $(2000,2008)$ takes $\mathrm{CP}_{\text {inf }}$ not to be a phase in

\footnotetext{
${ }^{31} \mathrm{~A}$ reviewer pointed out that the issue of copy pronunciation requires clarification if, as we originally submitted, the lexical content of the reflexive element corresponds to the NP complement to D, and this NP remains in situ. Our current modification solves this problem if the domain of lexicalisation involves a larger constituent of $\left[_{\mathrm{DP}}\left[_{[\varphi]\left[\mathrm{var}_{-}\right]} \mathrm{D}\right]\right.$ $\left.\left[0_{\mathrm{D}}[\mathrm{NP}]\right]\right]$. Alternatively, the operation of moving a null $\left[_{[\varphi]\left[\mathrm{var}_{-}\right]} \mathrm{D}\right]$ alone could work like $w h$-movement in languages with null wh-operators (e.g. Korean). That is, just like the $\mathrm{D}^{0}$ head of the $\mathrm{D}$-bound, a null wh-operator moves for interpretation reasons (at LF) and determines the interpretation of the $w h$-phrase as a question phrase, but only the NP complement is lexicalized. Also, as suggested by the reviewer, the Polish reflexive clitic się, the distribution of which overlaps with the landing sites of the $\mathrm{D}^{0}$ head (see $23 \mathrm{~b}$ ), could have the structure $\left.{ }_{\mathrm{DP}}\left[_{[\varphi][\text { var:1] }} \mathrm{D}\right]\right]$ in which the $\mathrm{D}$ bound is a projection of the $\mathrm{D}^{\min / \mathrm{max}}$ in terms of BPS.
} 
the context of his Agree-based control theory and Zubkov (2018) does not take either $\mathrm{CP}_{\text {inf }}$ or $v \mathrm{P}$ to be phases in the context of his Agree-based theory of binding. A recent proposal in the spirit of restructuring/reanalysis of infinitive complements resulting in the removal of the CP projection level is formulated in Müller $(2017,2018)$. He submits that the menu of basic syntactic operations needs to be enriched with the operation Remove, a mirror reflection of the operation Merge. Remove cancels already constructed phrase markers in a very regular manner, it is subject to the Strict Cycle Condition, it is feature driven (in the case of cancelling CP the relevant feature rests on the selecting matrix verb) and affects either maximal projections or heads. In the latter case both the head and its projections disappear, with the former dependents of this head reassociated with the selecting $\mathrm{V}$ (possibly as its specifier(s)), as TP becomes its complement following the removal of CP. The consequence of $\mathrm{C}$ (and $\mathrm{CP}$ ) removal from the structure is the reanalysis of a bi-clausal structure to a mono-clausal context and the disappearance of the CP phase, opening the way to long-distance upward probing by the [var:_] probe. Last but not least, Bošković (2007) submits that Agree is not limited by the PIC to search for potential goals and transgresses phase boundaries.

The key feature of our technical account of both the subject orientation of reflexives and the intricate Spell-Out pattern of indexically dependent reflexive and pronominal possessives consists in (i) positing late lexicalisation of the D-bound/Index in the derivation (Nikolaeva 2014; Safir 2014), depending on the Lexicalisation Rule in (35), (ii) positing two features on the D-bound/Index which drive its derivational behaviour: the interpretable but unvalued [var:_] feature that probes upwards in search for the antecedent (Hicks 2009), and the set of $\varphi$-features including [ - val, person] shared with and attracted by the nearest relevant head $v /$ T (Béjar \& Rezac 2009; Franks 2017).

The account presented above for Polish does not seem limited only to this language but is applicable to all languages boasting reflexive possessives in their grammatical inventory. ${ }^{32}$ This group involves both NP-languages and certain DP-languages. Here is why: in our discussion thus far we have taken care to adhere to the rules of the broadly defined phase-based syntax of Chomsky (2000, 2001, 2008). Crucially, the Phase Impenetrability Condition (PIC) and the Minimal Link Condition (MLC) are either strictly adhered to or observed indirectly with help from the Principle of Minimal Compliance (PMC). No movement or upward Agree relation violates these conditions. However, a phase boundary, such as DP (but not NP), should block a relation holding between a reflexive element placed in the complement of D and a DP-external antecedent. ${ }^{33}$ Whenever grammatical, the reflexive element is expected to be placed at the edge of the DP-phase. Reuland (2011), relying of the articulated structure of the nominal phrase in Longobardi (2001), suggests that the DP projection excludes the reflexive possessive unless the Determiner is (or can be) postnominal. This idea is subsequently developed in Despić (2015). Despić observes that not only NP languages have reflexive possessives but also DP-languages where the Determiner can postmodify the lexical noun:

\footnotetext{
${ }^{32} \mathrm{We}$ are grateful to a reviewer for drawing our attention to this comparative issue.

${ }^{33}$ While Bošković (2005) claimed that simple NPs were not phasal projections at all, his later publications (Boskovic 2012) made the claim that the maximal nominal projection was a phase (so the NP as well). The difference between the two language groups with respect to LBE was the placement of the adjective/possessive at the edge as an adjunct (Slavic) or its placement deeper within the DP structure (away from the edge).
} 


\begin{tabular}{|c|c|}
\hline & No Reflexive possessives \\
\hline $\begin{array}{c}\text { Prenominal definiteness } \\
\text { marking }\end{array}$ & $\begin{array}{c}\text { (A) Afrikaans, Dutch, Frisian, English, German, Italian, } \\
\text { Misantla Totonac, Modern Greek, Portuguese, Spanish }\end{array}$ \\
\hline & \multicolumn{1}{|c|}{ Reflexive possessives } \\
\hline $\begin{array}{c}\text { Postnominal definiteness } \\
\text { marking }\end{array}$ & $\begin{array}{c}\text { (B) Bulgarian, Danish, Faroese, Icelandic, Koromfe, } \\
\text { Macedonian, Norwegian, Romanian, Swedish }\end{array}$ \\
\hline No definiteness marking & $\begin{array}{c}\text { (C) Belorussian, Chinese, Czech, Dolakha Newar, Hindi-Urdu, } \\
\text { Japanese, Kannada, Kashmiri, Korean, Latin, Lezgian, } \\
\text { Malayalam, Moseten, Old Church Slavonic, Persian, Polish, } \\
\text { Proto-Slavonic, Russian, Serbo-Croatian, Slovak, Slovenian, } \\
\text { Sorbian, Tamil, Thai, Turkish, Ukrainian }\end{array}$ \\
\hline
\end{tabular}

Despić proposes a theoretical account of this regularity based on the idea, present in Szabolcsi (1983) and Kayne (1994), that the possessor in languages from the group (A), such as English or Italian, is not in fact placed in [spec, DP] but in a lower projection of Possessive Phrase (PossP), which is a complement to D. Both positions are filled lexically in the Italian example:

(60) il mio libro (Italian)

the my book

'my book'

(61) $\left[\mathrm{DP} D\left[\right.\right.$ PossP $^{*}{ }^{\mathrm{Refl} /}{ }^{\mathrm{OK}}$ Pron [Poss' ${ }^{2}$ Poss [NP ...]]]]

Such a placement makes it impossible for the possessive to be expressed in a reflexive form, as the reflexive cannot become involved in the binding relation across the DP-phase. Yet, in languages where the Determiner can be postnominal, the head D bears an Edge Feature (EF) that forces the constituents in Poss and in [spec, PossP] to move to the phase edge positions of D and [spec, DP], respectively. In concrete terms, for Scandinavian reflexive possessive constructions Despić relies on the analysis of Norwegian in Delsing (1993). But for a few details, the underlying structure is similar to (62) here, where the possessor (Per) originates within the NP and moves successive-cyclically to [spec, DP], while the possessive marker-sitt originates in the head of Poss (just like the possessive reflexive/pronoun) but it moves to D via head movement:
a. Per sitt hus
Per REFL house
'Per's house'

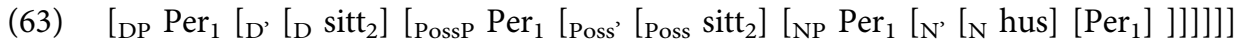

These movement operations are all important, as they now bring the reflexive to the edge of the DP phase and allows for its association with the outside antecedent. The Bulgarian possessive follows a similar route to the edge of DP. Consequently, not only Polish and Russian but also Bulgarian and Norwegian have reflexive possessives: 
(64) $\mathrm{John}_{1}$ ga $\operatorname{Per}_{2} \quad\left[\sin _{1 / * 2} \quad\right.$ jakke $]$

John gave Peter his/REFL jacket

'John gave Peter his jacket.'

We know that in these languages the reflexive possessives are subject-oriented, just like in Polish, as evident from the seminal covert movement-based account of Norwegian reflexives in Hestvik (1992), applicable to other Scandinavian languages. Our account is compatible with his. ${ }^{34}$

\section{DATIVE ARGUMENTS AND THEIR BINDING DOMAINS}

In general, our analysis can be used as a detector for the position in which a given antecedent is placed with respect to the heads $v / T$ in subject-oriented binding languages such as Polish.

\subsection{Non-experiencer Datives}

Any dative antecedents placed below $v$, so within VP, are predicted not to be able to function as antecedents for reflexive pronouns/reflexive possessives. From the perspective of our discussion all ditransitive constructions show a crucial property, namely the superior object cannot function as an antecedent for the reflexive possessive in the other object; it can only antecede a pronominal possessive: ${ }^{35}$
a. $\operatorname{Jan}_{1}$
pokazał $\mathrm{Marii}_{2}$
swoje $_{1 / \star 2} /$ jej $_{2}$ zdjęcie.
Jan.NOM showed Maria.DAT self/her
picture.ACC
'John showed Mary his/her picture.'
b. $\operatorname{Jan}_{1}$ pokazał Marię̧ swojej $_{1 / \star 2} / \mathrm{jej}_{2}$ przełożonej. Jan.NOM showed Maria.ACC self/her supervisor.DAT 'John show Mary to his/her supervisor.'

This state of affairs is expected on the basis of the derivations analyzed in detail in (36)-(37) above.

\footnotetext{
${ }^{34}$ The topic that we intend to turn to next is a comparative analysis of all NP-languages and postnominal DP-languages, examining the issue of a plausible co-occurrence in them of the phenomena of Left Branch Extraction, possessive reflexive placement and the Extended Anaphor Agreement Effect. This step is, however, beyond the scope of this contribution.

${ }^{35}$ It must be noted that this conclusion does not hold for all Slavic languages. For example, Marvin and Stegovec (2012) show that in Slovenian, a quantifier in the higher dative object can bind a reflexive possessive in the lower object, as in (i).

\begin{tabular}{|c|c|c|c|c|c|}
\hline $\begin{array}{l}\text { Tat }_{j} \\
\text { thief }_{j}\end{array}$ & $\begin{array}{l}\text { Je } \\
\text { AUX }\end{array}$ & $\begin{array}{l}\text { vrnil } \\
\text { return.PAST }\end{array}$ & $\begin{array}{l}\text { [vsakemu } \\
\text { each }\end{array}$ & $\begin{array}{l}\text { oškodovancu] } \\
\text { victim.DAT }\end{array}$ & $\begin{array}{l}{\left[\text { svoj }_{i, j}\right.} \\
\text { his }\end{array}$ \\
\hline
\end{tabular}

'The thief returned every victim his car.'/The thief returned every victim his (the thief s) car.'
} 
The dative of possession seems to behave like a regular VP-internal dative object. Polish has a construction where the dative-marked nominal represents the thematic role of possessor, correctly captured in the English translation:

a. $\operatorname{Jan}_{1}$ złamał Tomkowi 2 [(* ${ }^{\star}$ swoją̧ $_{2} /$ jego $\left._{2}\right)$ ulubioną kredkę $]$. Jan.NOM broke Tomek.DAT self/his favourite pencil.ACC 'Jan broke Tomek's favourite colour pencil.'

b. Maria ${ }_{1}$ wybiła Tomkowi 2 [( ${ }^{*}$ swoją̧ $_{2} /$ jego $\left._{2}\right)$ nową złotạ plombȩ $]$. Maria.NOM knocked-out Tomek.DAT self/his new golden filling.ACC 'Maria knocked out Tomek's new golden filling.'

The fact that only the possessive pronoun is the correct co-indexed bound form indicates that the dative of possession is placed only as high as [spec, VP], as $\mathrm{NP}_{2}$ in (13), and the head $\left.{ }_{[\varphi]\left[\mathrm{var}_{-}\right]} \mathrm{D}\right]$ is raised to $v / \mathrm{T}$, outside of its c-command domain:

$\left[{ }_{v \mathrm{P}} \operatorname{Jan}_{[\mathrm{var}: 1], \mathrm{NOM}}\left[{ }_{[\varphi][\mathrm{var}: 2]} \mathrm{D}\right]_{2}-v\right.$ broke $\left[{ }_{\mathrm{vP}} \operatorname{Tomek}_{[\mathrm{var}: 2], \mathrm{DAT}}\left[{ }_{\mathrm{v}}, \mathrm{V}\left[_{\mathrm{NP}}\left[{ }_{\left[{ }^{*} \varphi\right][\text { var:2] }} \mathrm{D}\right]\right.\right.\right.$ [favourite pen]]]]]

The same effect holds of unaccusative constructions used with dative possessors:

a. Marii stłukła się ${ }^{\star}$ swoja/jej ulubiona filiżanka.

Maria.DAT broke REFL self s/her favourite cup.NOM

'Maria's favourite cup broke up.'

b. [TP/FinP Maria ${ }_{[\operatorname{var}: 1], \mathrm{DAT}} \ldots\left[_{[\varphi][\text { var:1] }} \mathrm{D}\right]-\mathrm{T}$ broke

[vP [var:1],DAT [v' V [NP [ [ $\varphi][$ [var:1] D][favourite cup]]]]]

Only the possessive pronoun is admissible here, which indicates that probably the dative antecedent is placed inside VP. We assume that it is in the [spec, VP] position. ${ }^{36}$

In this context, consider an example of the impersonal passive construction with a dative argument: ${ }^{37}$

${ }^{36}$ Similarly, the accusative argument in the adversity impersonal construction is unable to bind an anaphor (Lavine \& Franks 2008; Witkoś et al. 2018), which we take to indicate that its A-chain does not extend beyond VP:

(i) Marynarza zabiło po jego/*swojej wachcie.

sailor.ACC killed.3SG.N after his/selfs watch

'A/the sailor was killed after his watch.'

(ii) [тр ... [Tт T [ ${ }_{v \mathrm{P}}$ CAUSE Index- $v$ [vp sailor ${ }_{\mathrm{ACC}}$ killed-V [pp after [Index [watch]]]]]]

The head [ $[\varphi][$ var:_] $\mathrm{D}]$ is raised to its reflexivization site at $v / \mathrm{T}$, beyond the c-domain of the accusative-argument in [spec, VP]. Although the accusative NP is moved further on to some clause-initial position in the left periphery of the clause, this movement does not extend its binding domain. This observation in fact confirms the analysis proposed for this construction in Lavine and Franks (2008), who argue that the accusative NP is a regular internal argument of the verb (object), with an abstract CAUSE element serving as the external one.

${ }^{37}$ A more recent analysis of Impersonal constructions with Dative Experiencers in Polish is proposed in Willim (2018). 


\section{(69) Marii pokazano ${ }^{\star}$ swoją/jej nową koleżankę. Maria.DAT shown.IMPRS self's/her new.ACC friend.ACC \\ 'Maria was shown her new friend.'}

Despite the fact that the dative argument is placed in the left peripheral position in the clause and on many analyses, it occupies [spec, TP] (see Bailyn 2014), it can only function as an antecedent to a pronominal possessive. We take this fact to indicate that the case position of this argument is fairly low, probably [spec, VP], as any ordinary dative object of a ditransitive construction and its movement to the TP area does not extend its binding domain. ${ }^{38}$ The head [ $[\varphi][v a r: 1]$ D] has its [var:_] feature valued in the base position and its [-val, person] feature is attracted by an analogous feature on $\mathrm{T}$ :

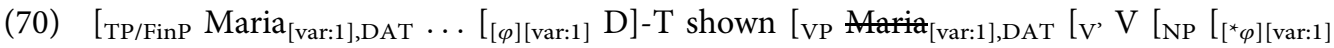
D] [new friend]]]]]]

Concluding, non-experiencer datives have their base potion relatively low in the clausal structure, inside the VP. In this sense they contrast sharply with experiencer datives.

\subsection{The base position of the Dative Experiencer}

Psychological predicates with dative experiencers fall into two classes: non-verbal predicates and verbal ones. The chief source of differences between them in terms of binding properties of their dative arguments stems from the fact that only the latter allow for nominative T/SM (Target/Subject Matter) arguments and binding into these shows considerable speaker variation.

Let us present a detailed account of the derivation of a non-verbal predicate with DAT OE, known from (3):
a. Marii $_{1}$
było
żal
siebie $_{1} /{ }^{*}$ jej $_{1}$
(samej).
Maria.DAT was.3sG.N sorrow.3sG.M self.GEN/*?her.GEN (alone)
'Maria felt sorry for herself.'
b. Marii $_{1}$ było żal swojej $_{1} /$ jej $_{1}$ koleżanki.
Maria.DAT was.3sG.N sorrow.3sG.M self s.GEN/her.GEN friend.3sG.F.GEN
'Maria felt sorry for her female friend.'

Either order of Agree operations (Agree for [var:_] or Agree for [_val, person] $/ \varphi$-features) leads to the configuration in which $\left[_{[\varphi]\left[\text { var_}_{-}\right]} \mathrm{D}\right]$ is placed in a position adjoined to $v$. When it stays there, the Lexicalisation Rule in (35) predicts the Spell-Out of the reflexive possessive, but when it (optionally) rises to $\mathrm{T}$, the possessive is spelled out as pronominal. XP marks any constituent fronted to the clause initial position: ${ }^{39}$

\footnotetext{
${ }^{38}$ The same conclusion is reached in Moore and Perlmutter (2000) for Russian impersonal passives.

${ }^{39}$ In terms of Minimality considerations, the movement of the NP Maria $a_{\text {DAT }}$ to the position of XP facilitates an unobstructed relation between [_val person] on T and [ $\left.{ }_{[\varphi][\text { var:1] }} \mathrm{D}\right]$ and the attraction of the latter to the former.
} 
$(72)$

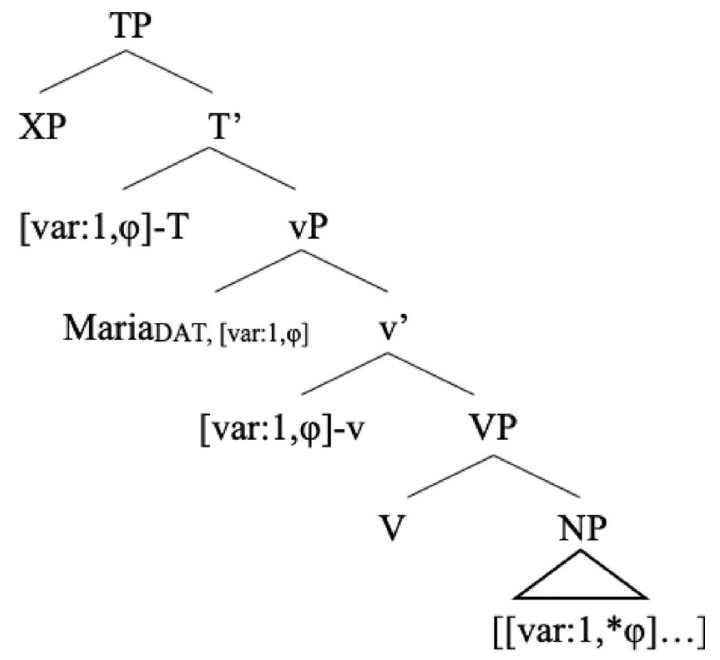

The derivation above is markedly different from equivalent constructions with nominative subjects and a corresponding verbal predicate $\dot{z}$ atować 'feel pity' in a predictable manner. In (73a,b), the subject occupies [Spec, TP], the highest A-position in the clause, so in both corresponding derivations the head $\left.{ }_{\left[{ }_{[}\right][\text {var:1] }} \mathrm{D}\right]$ adjoined to $v / \mathrm{T}$ is c-commanded by the NP covalued for the [var:_] feature (or its copy) and the foot of its chain must be spelled-out as a reflexive: ${ }^{40}$

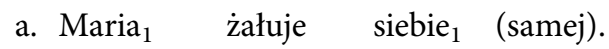
Maria.NOM feels-pity self.GEN alone

'Maria feels pity for herself.'

b. Maria $_{1}$ żałuje swojej ${ }_{1} /{ }^{*}$ jej $_{1}$ koleżanki.

Maria.NOM feels-pity self $s /{ }^{\star}$ her friend

'Maria feels pity for her friend.'

The most frequently researched verbal psychological predicate in Polish is podobać się 'appeal to' (see Bondaruk \& Szymanek 2007; Miechowicz-Mathiasen \& Scheffler 2008; Żychliński 2013; Jiménez-Fernández \& Rozwadowska 2016; Bodaruk et al. 2017). Its distinctive property is the fact that it selects for the Experiencer in dative and the Cause/Target of Emotion

\footnotetext{
${ }^{40}$ The relevant representations take the following form:

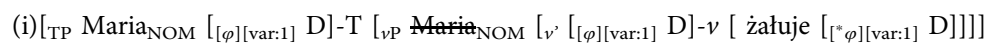

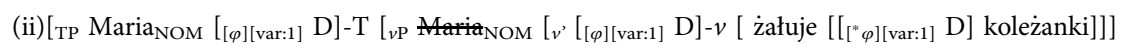


in nominative. It has also been noticed that the binding potential of its dative-marked argument differs from the dative of non-verbal psych-predicates: ${ }^{41}$

(74) Maria $_{1}$ podobała się sobie $_{1}$ w lustrze.

Maria.NOM appealed REFL self.DAT in mirror

'Maria appealed to herself in the mirror.'

(75) Maria $_{1}$ podobała się swojemu ${ }_{1} /{ }^{*}$ jej $_{1}$ koledze $\mathrm{z}$ ławki.

Maria.NOM appealed REFL self $s{ }^{\star}$ her friend.DAT from school_desk

'Maria appealed to her school desk friend.'

(76) Marii $_{1}$ spodobała się nawet ?\%ona ${ }_{1}$ (sama) $/{ }^{*}$ sobie $_{1}$ (sama) w lustrze.

Maria.DAT appealed REFL even she.NOM alone/*self.NOM alone in mirror

'Even herself in the mirror appealed to Maria.'

(77) Marii $_{1}$ podobał się ${ }^{*}{ }^{*}$ wó $_{1} /$ jej $_{1}$ kolega $\mathrm{z}$ ławki.

Maria.DAT appealed REFL ${ }^{\star}$ self s/her friend.NOM from school_desk

'Her school desk friend appealed to Maria.'

(78) Janowi $i_{1}$ spodobały się listy od swoich $_{1} /$ jego $_{1}$ fanek

Jan.DAT appealed REFL letters from selfs/his fans

'Letters from his fans appealed to Jan.'

In general, if the dative Experiencer of a psychological verb is in [Spec, $v \mathrm{P}]$, we expect to see optionality with the pronominal vs reflexive possessive, similar to that with non-verbal psychpredicates, but this is not the case. ${ }^{42}$ The pie can be partitioned into three uneven sections. Most native speakers prefer for the dative Experiencer to bind pronominal possessives, see (77). Quite a few allow the dative Experiencer to bind a possessive reflexive but typically in contexts where the reflexive is embedded deep in the nominative constituent and thus bears a different case, see (78). However, an internet search provides a small number of examples where the possessive reflexive can be bound by the dative Experiencer in the nominative NP, see (79)-(81):

${ }^{41}$ Franks (1995: 253) observes a corresponding contrast for Russian.

${ }^{42}$ Other similar verbs in Polish are dokuczać 'tease, vex', nudzić 'bore' and szkodzić 'harm':

(i) Marii $_{1}$ dokuczał ${ }^{*}{ }^{*}$ swó ${ }_{1} /$ jej $_{1}$ kolega $\mathrm{z}$ ławki.

Maria.DAT teased *self s/her friend.nom from school_desk

'Her school desk friend teased to Maria.'

(ii) Janowi ${ }_{1}$ szkodzily listy od ?swoich $_{1} /$ jego $_{1}$ fanek.

Jan.DAT harmed letters from selfs/his fans

'Letters from his fans harmed Jan.' 
(79) $\mathrm{Mi}_{1}$ się swój ${ }_{1}$ głos podoba. me.DAT REFL my voice like 'I like my voice.'

(Miechowicz \& Scheffler 2008: pp; corpus search)

(80) Paniom bardziej podobał się [swój wygląd], czuły się spełnione women.DAT more appealed REFL self's look.NOM they.felt REFL accomplished i szczęśliwe.

and happy.

'Their looks appealed to the women more, they felt accomplished and happy.' (source: https://zaradnakobieta.pl/183.dlaczego-warto-zaczac-uprawiac-joge)

(81) Sama mam koleżankę, która pomimo miseczki 70d chciałaby mieć silikony I_myself have friend.F who although size 70d would.like have silicon ponieważ nie podoba się jej [kształt [swoich naturalnych piersi]]. because not appeals REFL her.DAT shape.NOM selfs natural breasts.GEN 'I myself have a female friend who, although she her size is $70 \mathrm{~d}$, would like to get silicon breasts because the shape of her natural breasts does not appeal to her.' (source: http://zdrowie.gazeta.pl/Zdrowie/51,107103,12809307.html?i=1)

The inconclusive data above lead to conflicting views on the position of the dative OE and the position of the nominative argument. ${ }^{43}$ Jimenez-Fernandez and Rozwadowska (2016) assume that its A-position is in [spec, VP] (and the preverbal position is in an articulated CP area). Bondaruk and Szymanek (2007), Tajsner (2008) and Bondaruk (2017) propose that the dative experiencer is in [spec, $v \mathrm{P}$ ], as its binding scope is different from that of dative goals. Miechowcz-Mathiasen and Scheffler (2008) claim that the dative Experiencer reaches as high as [spec, TP].

We propose that the DAT OE is placed higher than the goal/benefactive but lower than the nominative subject in the relevant sense. There are two reasons that force this conclusion on us. First, some semantic factors support higher placement of dative OEs in the clausal structure in comparison with dative goals/benefactives. Cuervo (2003) argues that the dative argument of gustar, the Spanish equivalent to podobać się 'appeal to' seems to be licensed by a high applicative in the sense of Pylkkänen (2002). This is because the nominative argument is not involved with it in any relation of possession or location that is typical of 'low' applicatives in (82a,b), where Maria's habitual possession of the pen is implied, so (82b) can only mean that the pen was

\footnotetext{
${ }^{43} \mathrm{~A}$ reviewer raises a question of a potential correlation between the morphological form of the possessive (reflexive vs. pronominal) and alienable vs. inalienable possession (one's friend from (77) vs. one's looks from (80)). We have not tested this variable in our experiments but we are certain that this interpretive dimension deserves attention in our future research on this topic.
} 
Mark's and it was in Maria's possession only temporarily. No possession or location is implied in (83).
a. Marii złamał się długopis.
Maria.DAT broke REFL pen.NOM
'Maria broke a pen.'
b. \#Marii złamał się długopis Marka.
Maria.DAT broke REFL pen.NOM Mark's
'Maria broke Mark's pen.'

(83) a. Marii podoba się długopis Marka.

Maria.DAT appeal-to REFL pen.NOM Mark's

'Mark's pen appeals to Maria.'
b. Marii było żal długopisu Marka.
Maria.DAT was.3sG.NEUT sorrow pen Marek.GEN
'Maria was sorry about Mark's pen.'

In the context of the solution proposed here, the dative argument corresponding to the 'high' applicative is placed in [spec, $v \mathrm{P}$ ], while the one in the 'low' applicative is in [spec, VP]. Hence we account for the profound interpretive difference between (82) and $(83){ }^{44}$

Second, results of a series of experiments reported in Gogłoza et al. (forthcoming-b) confirm that acceptability of the binding of reflexives embedded in nominative themes is strongly influenced by the AAE and that DAT OEs are in fact merged in a position from which they can bind anaphors. The aim of one experiment was to test this assumption by comparing the contexts in which the possessive reflexive is embedded in a complement NP of a nominative theme, thus bearing genitive case, as in (81) and (84), to the ones in which it modifies a nominative theme, as in (77) and (79)-(80). The results showed that embedding the reflexive significantly improved binding by DAT OEs, although it did not yield full acceptability:

\footnotetext{
${ }^{44}$ There is evidence that the nominative reflexive possessive can be legitimately bound under certain conditions. Tajsner (2008: 337) observes that swó $j_{\mathrm{NOM}}$ 'self $\mathrm{s}_{\mathrm{NOM}}$ ' can be bound, provided it does not form a chain with T, e.g. with a nominative-taking preposition jak 'like':
}
(i) Jarek $_{1}$ wyglạda jak [swój ${ }_{1} /$ jego $_{1}$ brat bliźniak].
Jarek.NOM looks like self s/his own twin brother.NOM
'Jarek looks like his twin brother.'


(84) Janowi nie spodobała się [koleżanka [? swojej/jego siostry]]. Jan.DAT not appeal REFL friend.NOM self s/his sister.GEN 'His sister's friend did not appeal to Jan.'

This result could not be explained under the assumption that DAT OEs are not proper anaphor binders, making them akin to object binders. If this were the case, embedding should not lead to any improvement, which was shown for object binders in DOCs in another study by Gogłoza et al. (forthcoming-a). The results of that experiment revealed that the higher object could not bind the reflexive in the lower object and embedding the reflexive in a complement NP did not improve binding.

Binding by DAT OEs, on the other hand, is significantly facilitated when the AAE is, to some extent, controlled for with the use of embedding. These results draw a clear division line between the position of goal/benefactive datives and DAT OE datives; the former are VP-internal, while the latter are VP external. Hence, at least for Polish, we cannot accept proposals where DAT OE constructions are double object unaccussatives, as in the original proposal in Belletti and Rizzi (1988).

At the same time the DAT OE does not occupy a clausal position which is as high as that of the nominative subject in the following sense: although they both originate in $[$ spec, $v \mathrm{P}$ ], there is a difference in how high their A-chains reach, which determines their command scope. The trivial A-chain of the DAT OE starts and finishes in [spec, $v \mathrm{P}]$, while the A-chain of the nominative subject begins in [spec, $v \mathrm{P}$ ] but terminates in [spec, TP]. Thus assuming the clitic-like movement of the D-bound/Index to either $v$ or T and the Lexicalisation Rule in (35), the DAT OE can function as antecedent to either a reflexive or a pronominal possessive, whereas the nominative subject must always function as an antecedent to a reflexive possessive in a simple clause. This is because either its copy in [spec, $v \mathrm{P}$ ] or the subject itself in [spec, TP] form specifiers of heads to which the D-bound/Index is adjoined on the strength of the derivations in (72) above and (88) below.

We believe that the results of the experimental studies exemplified in (84) above, as well as examples (79)-(81) lead us to treat with caution proposals where the nominative object is placed excessively high. For instance, Cuervo (2003) argues that the dative OE is placed in a higher position, as the nominative Theme occupies a high position of [spec, vP]. Germain (2015), assuming the framework of Nikolaeva (2014), proposes a similar solution for Russian and she relies on the following representation:

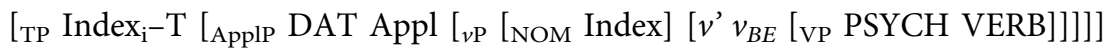

Technically, this proposal provides for the lack of reflexive possessives in nominative NPs in (77) above. Because the D-bound/Index cannot lower to $v$ to adjoin to it, Appl is not a designated reflexivization site by definition, and the designated lexicalization site $\mathrm{T}$ is too high to be locally c-commanded by the DAT OE from the [spec, $v \mathrm{P}]$ position. Yet, the 
structure in (85) makes the prediction that examples (79)-(81) should never be acceptable, even marginally. Furthermore, even embedding the D-bound/Index within a nominativemarked NP argument in (78) and (81) should not allow for its lexicalization as a reflexive. Additionally, this proposal would imply that the DAT OE in structures involving the predicate podobać się 'appeal to' occupies a different position from the DAT OE of nonverbal psych predicates in (3).

Therefore, we submit that the dative Experiencer occupies the position of [spec, $v \mathrm{P}]$, the same as the DAT OE of the predicate $\dot{z} a l$ 'sorrow' in (3) and (71)-(72) above: ${ }^{45}$

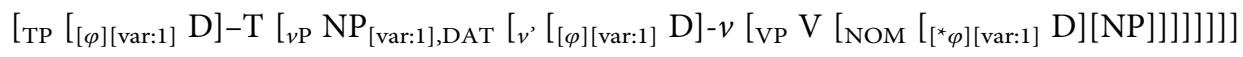

The placement of the DAT OE in this position, the hypothesis of D-bound/Index raising in a clitic-like fashion, together with the Anaphor Agreement Effect pertinent to nominative themes, discussed in the next section, provide for an empirically adequate picture of A-binding by the DAT OE.

Consequently, a verbal psych predicate with DAT OE and a nominative argument has two representations, depending on whether or not the nominative argument overtly moves to the [spec, TP] position. The D-bound/Index can be placed on the nominative argument only very marginally, when the nominative remains in situ inside VP. The derivation is then analogous to (72) above, but the expected lexicalisation in the form of the reflexive possessive is distorted by the Extended Anaphor Agreement Effect (Rizzi 1990a) discussed in section 5 .

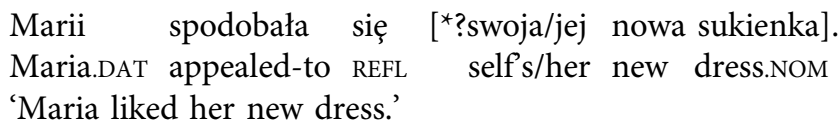

${ }^{45} \mathrm{~A}$ similar structure is proposed in Bondaruk and Rozwadowska (2018) and Klimek and Rozwadowska (2004) for an analysis of accusative OEs, exemplified by the following sentence from Bondaruk and Szymanek (2007) in (i). (ii) Contains a variation of this example with possessives:

(i) Maria brzydzi się swoim zachowaniem, aż [odrzuca ją̧ od $\operatorname{siebie}_{1}{ }^{*}{ }^{*}$ niej $\left._{1}\right]$. Mary.NOM despises REFL self's behaviour.INST so_that puts_off her.ACC from herself.GEN/her.GEN 'Mary despises her own behaviour so much that it puts her off herself.'

(ii) Marię odrzuca od [listów [swojego/jej byłego męża]].

Maria.ACC puts_off from letters.GEN selfs.GEN/her.GEN ex husband.gEN

'Maria is put off by letters of her ex-husband.'

The binding potential of ACC OEs is heavily influenced by the AAE. See Witkoś et al. (2018) and Witkoś et al. (2020) for a more detailed account of these facts. 
$(88)$

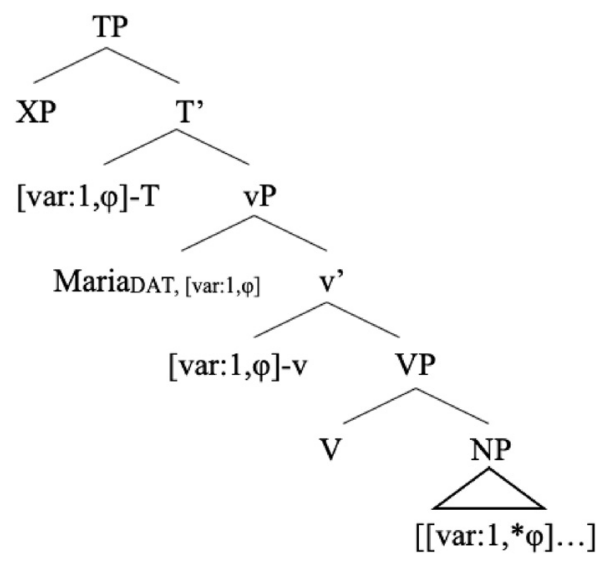

When the D-bound/Index is placed within the dative OE, its [person] feature of the $\varphi$-feature complex is valued against T, while its [var:_] feature is valued against the subject in [spec, TP]:

(89) Aktorka spodobała się [swoim/??jej nowym fanom]. actress.NOM appealed_to REFL selfs/her new fans.DAT 'The actress appealed to her new fans.'

(90)

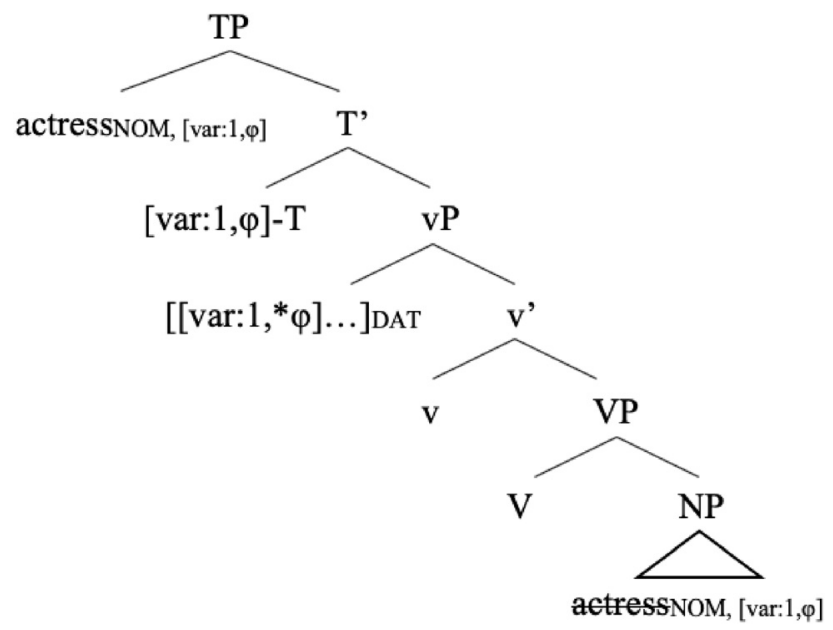


The nominative antecedent forces the presence of the reflexive possessive, as expected. ${ }^{46}$

Let us complete the review of constructions where the dative-marked NP has [spec, $v \mathrm{P}]$ as its case position. As observed in Dziwirek (1994), derived psych verbs license DAT OE arguments. They can optionally function as antecedents to reflexive possessives, which points to their placement in $[\mathrm{spec}, v \mathrm{P}]$ on our analysis:
a. Janowi spało $_{1}$
się dobrze $\mathrm{w}$ swoim $_{1} /$ jego $_{1}$
nowym łóżku. Jan.DAT slept.3sG.NEUT REFL well in self s/his new bed 'Jan slept well in his new bed.' (intd: Jan found his new bed comfortable)
b. Marii ${ }_{1}$ prowadziło się dobrze ten swój ${ }_{1} / \mathrm{jej}_{1}$ nowy samochód. Maria.DAT drove.3SG.NEUT REFL well this self s/her new car 'Maria drove her new car well.' (intd: Maria found driving her new car easy.)

These constructions show productive dative inversion with respect to typically unergative verbs. ${ }^{47}$ The binding relations in (91) indicate that all DAT OEs are 'birds of a feather that flock together': they flock at $[\mathrm{spec}, v \mathrm{P}]$.

\section{EXTENSION TO THE ANAPHOR AGREEMENT EFFECT}

Now we return to the question of why DAT OEs do not function as antecedents for reflexive possessives in theme arguments marked for nominative case, though the structure in (86) predicts that they should. We credit this fact to an extension to the Anaphor Agreement Effect: ${ }^{48}$

(92) Anaphors do not occur in syntactic positions construed with agreement.

\footnotetext{
${ }^{46} \mathrm{~A}$ version of the same example with a QP subject is similar to (72), which confirms that LF-relevant binding is involved in this relation:

(i) Każda aktorka spodobała się [swoim/??jej nowym fanom]. every actress.NOM appealed_to REFL selfs/her new fans.DAT 'Every new actress appealed to her new fans.'

${ }^{47}$ Thus the examples in (74) above are close derivational relatives of the following unergative constructions:

(i) $\operatorname{Jan}_{1} \quad$ spał $\quad \mathrm{w}$ swoim $_{1} /$ jego $_{1}$ nowym łóżku.

Jan.NOM slept.3SG.M in self s/his new bed

'Jan slept in his new bed.'

(ii) Maria $_{1}$ prowadziła ten swój ${ }_{1} / \mathrm{jej}_{1}$ nowy samochód.

Maria.NOM drove.3SG.F this self s/her new car

'Maria drove her new car.'

${ }^{48}$ A related view is articulated in Bondaruk (2017), who attributes the lack of binding by dative OEs into nominative arguments to the AAE.
} 
Rizzi (1990: 32-33) reports the following contrast in Italian: a dative experiencer can bind an anaphor as long as it is not nominative, so since importare 'matter' takes a genitive theme, this theme can be bound, while a nominative argument of interessare 'matter' cannot:
a. A loro importa solo di se stessi.
to them matters only of themselves
'Only they themselves matter to them.'
b. ${ }^{\star}$ A loro interessano solo se stessi.
to them interest only themselves
Intended: 'Only they themselves are interesting to them.'

Significantly, however, dative experiencers can function as binders once the AAE is controlled for, as in (76a). The same picture obtains with Polish dative experiencers in (3).

Rizzi (1990) and Woolford (1999) outline two possible theoretical reasons for why (92) should hold. Both centre on the idea that subject/verb agreement expression on Infl/T has a pronominal nature (Agr on Infl/T functions like a pronoun with respect to the Binding Principles). The first one is based on the concept of the Referential Autonomy Hierarchy holding with chains:

$$
\begin{aligned}
& \text { Referential Autonomy Hierarchy: } \\
& \text { R-expressions > pronouns > anaphors }
\end{aligned}
$$

The argument of a chain should be the most referentially autonomous element in the chain. If the agreeing element is the argument and the agreement itself is a non-argument, agreeing anaphors are ruled out. This is because anaphors are placed in a lower position on the scale in (94) than the agreement itself (pronominal). So, anaphors cannot function as arguments in the agreement chain. ${ }^{49}$

We propose to treat the Polish examples in (77) and (87) as a subcase of the AAE effects based on the process of percolation of the relevant features from the possessor to the projection of the NP it modifies. Such percolation of the features (for instance $w h$-features) or the referential index has been present in the generative literature for several decades now (see Cole, et al. (1993)). The phenomenon of feature/index propagation is multifaceted: the propagation is facilitated by morphological and syntactic conditions but also by semantic and pragmatic ones. For instance, Cole et al. (1993) discuss feature percolation phenomena in Chinese, where specifiers in NPs headed by inanimate Ns tend to act as antecedents to reflexives, which leads Cole et al. (1993) to call is the position of sub-command:

\footnotetext{
${ }^{49}$ The second element of a theoretical justification for (92) is related strictly to Binding Theory and the impossibility of satisfying both Principle A and Principle B in the same domain:

(i) *antecedent $t_{\mathrm{i}} \ldots$ [ [AgrP anaphor $_{\mathrm{i}}$ agreement $_{\mathrm{i} . . .}$ ]

In the structure of (i), assuming that the antecedent, AGR (pronominal) and the anaphor are in the same governing category/binding domain, Principles A and B mutually exclude each other: either the anaphor is bound by the antecedent, in line with Principle A, or the anaphor shares its index with AGR but this index must be different from (i), otherwise AGR will be bound by the antecedent, in violation of Principle B. In conclusion, the AAE prohibits nominative anaphors, because nominative elements also agree with the auxiliary/verb. In line with minimalist assumptions Reuland (2011) submits that reflexives have unvalued $\varphi$-features and the AAE is a consequence of them being $\varphi$ incomplete goals for the $\mathrm{T}$ probe.
} 


$$
\begin{aligned}
& {\left[\text { Zhangsan }_{\mathrm{i}} \text { de jiaoao }\right]_{\mathrm{j}} \text { hai-le } \mathrm{ziji}_{\mathrm{i} /{ }^{*} \mathrm{j}} .} \\
& \text { Zhangsan's pride hurt-ASP self } \\
& \text { 'Zhangsan's pride hurt himself.' }
\end{aligned}
$$

Instead of extending the definition of c-command, the authors submit that the [antecede] feature of the animate nominal in [spec, NP] percolates to the maximal projection of NP. They claim that feature percolation from the position of the specifier is more frequent than percolation from the position of the complement. It appears, however, that the set of semanticopragmatic conditions on percolation can apply only when the morpho-syntactic conditions are met first. In a way then, morpho-syntax paves the way for other conditions on percolation to set in. We concentrate only on the syntactic aspect below.

Our discussion of the Polish data above reveals that consequences of the AAE are subject to considerable language variation: nominative reflexive possessives are typically avoided by most speakers, although they are construed with agreement only indirectly: they agree (in case and $\phi$ features) with the NP they modify and this NP agrees with the auxiliary/verb. Yet, the structure we propose for pronominal possessive NPs is shown in (96). It is only natural to extend it to cases of reflexive possessives:

$$
\begin{aligned}
& \text { [NP jego [NP siostra] }] \\
& \text { his.GEN sister.NOM }
\end{aligned}
$$

'his sister'

$$
\begin{aligned}
& \text { [NP } \text { swoja [NP } \text { siostra]] } \\
& \text { self S.NOM sister.NOM }
\end{aligned}
$$

This structure may be quite ambiguous when the AAE applies, as the possessive element and the NP it modifies are equidistant to $\mathrm{T}$, according to the definition of the Minimal Link Condition: $:^{50}$

(98) Janowi nie spodobała się $\left[{ }^{*}\right.$ swoja/jego siostra $]$.

Jan.DAT not appleal REFL selfs/his sister.NOM

'His sister did not appeal to Jan.'

$$
\mathrm{T}_{\mathrm{AGR}, 2 / 1} \ldots \operatorname{Jan}_{\mathrm{DAT}, 1} \ldots\left[\mathrm{NP} \text { self } \mathrm{s}_{\mathrm{NOM}, 1}\left[\mathrm{NP} \operatorname{sister}_{\mathrm{NOM}, 2}\right]\right]
$$

In earlier sections we outlined two possible derivations for (98), depending on how high the head $\left[_{[\varphi][v a r: 1]} \mathrm{D}\right]$ rises. When it rises to $\mathrm{T}$ and it is not locally $\mathrm{c}$-commanded by the nominal

\footnotetext{
${ }^{50}$ In the context of the MLC, the proposed adjunction structure in (96)-(97) above implies that any probe c-commanding the NP goal also c-commands the adjunct, moreover, the NP category itself is not closer to the probe, as it does not ccommand the adjunct. Thus, if both the adjunct (Index) and [NP Index [NP .......]] share the features of the probe, they can be both related to it via Agree.
} 
specifier which valued its [var:_] feature (because simply there is no such specifier in the structure), the lexicalisation algorithm in (35), repeated in (100), predicts that the pronominal possessive form should be used.

(100) The Lexicalisation Rule:

The (bottom copy in the chain of the) D-bound/Index contributes to its lexicalisation as reflexive when (i) [ $\left.[\varphi]\left[\mathrm{var}_{-}\right] \mathrm{D}\right]$ is adjoined to $v / \mathrm{T}$ and (ii) the [var:_] feature of [ $[\varphi]\left[\mathrm{var}_{-}\right]$ $\mathrm{D}]$ is involved in Agree with the [var:x] feature of the NP in [spec, $v \mathrm{P} / \mathrm{TP}]$. The antecedent must occupy its case position. Otherwise the D-bound/Index is lexicalised as a pronoun.

But when the head $\left[{ }_{[\varphi][\text { var:1] }} \mathrm{D}\right]$ rises only to $v$, it is locally c-commanded by a nominal specifier which valued its [var:_] feature and the lexicalisation algorithm predicts that the reflexive possessive should be a legitimate outcome. Why is it a very marginal option then?

The ambiguity of T - NP probing in (99) is conditioned by two sources, one structural and the other morphological, necessarily operating in tandem:

(101) a. The possessive element and the NP it modifies are equidistant to T. The equidistance relationship in question may cause confusion as to which element is really in the Agree relation with Infl/T, the modified NP (with no consequence for the $\mathrm{AAE}$ ) or the possessive reflexive (violating the AAE).

b. The reflexive possessive bears two sets of $\varphi$-features. It bears the [var:_] feature of its antecedent (it has its $\varphi$-features deleted under identity with its antecedent) but it also bears $\varphi$-features (concord features) of the NP it modifies (including NOM case, as it is morphologically an adjective).

It must be observed right away that the structure in (99) with a pronominal possessive is unambiguous on account of the pronominal possessive bearing a different case (genitive) from the nominative of the NP it modifies, so the morphological ambiguity clause in (101b) does not hold of the pronominal possessive.

Technically, the ill-formedness of the use of the reflexive possessive in this construction receives two possible accounts. In the index-free theory, the deleted $\varphi$-features of the antecedent render the possessive reflexive an illicit (incomplete) goal for Agree with T, should $\mathrm{T}$ choose to access it in the ambiguous configuration of (99) above. ${ }^{51}$ In the parlance of the more traditional index-based theory, the reflexive possessive forces its referential index to propagate and thus represent the index of the entire NP. ${ }^{52}$

\footnotetext{
${ }^{51}$ See the derivation of (28d-e) and (98)-(99). Deletion of $\varphi$-features on the reflexive (they are recoverable from the antecedent) turns the reflexive into an illicit goal for T. This is exactly how the AAE is accounted for in Reuland (2011). In a similar vein, Progovac $(1992,1993)$ submits that reflexives are too 'weak' to license AGR. She submits that the reflexive, just like a trace, becomes empty in LF, as all its $(\varphi$-)features are recoverable form its antecedent. As Agr requires feature sharing, an empty element, bereft of $\varphi$-features, cannot share them with Agr, hence the AAE.

${ }^{52}$ In languages where possessives are genuine specifiers rather than adjuncts, possessive reflexives are allowed, as shown in Woolford (1999: 273-274).
} 
Let us follow the index-based perspective briefly and present a consequence of the structure in (99). Forced propagation of the index of the reflexive possessive (an element meeting both clauses of (101)) is not only equivalent to the data from Chinese and Korean discussed in Cole et al. (1993) but also quite similar to what Landau (2000: 109-111) observes for cases of Obligatory Control, where the controller (unexpectedly) does not c-command PRO but constitutes the specifier of a c-commanding DP:

(102) It would help Bill's $s_{1}$ development $\left[\mathrm{PRO}_{1}\right.$ to behave himself $f_{1}$ in public]

Landau proposes that a well-defined class of nouns denoting abstract notions reflecting the individuality of the controller ([X's NP]) allows for what he calls the logophoric extension of X:

(103) For the purpose of control, a logophoric extension [X's NP] is non-distinct from X: [X's $\mathrm{NP}] \rightarrow\left[\mathrm{X}^{\prime} \mathrm{S} \mathrm{NP}\right]_{1}$.

Thus, logophoric extension is a selective process that affects only one module of grammar and one aspect of interpretation: Control Theory. We would like to submit that an analogous process of reanalysis affects the adjunct/specifier structure:

(104) Extended Anaphor Agreement Effect:

Anaphors do not occur in syntactic positions construed with agreement directly (a) or indirectly (b):

a. Nominative anaphors do not exist in languages showing subject/verb agreement;

b. For the purpose of binding, an indexical extension $\left[\mathrm{X}_{\mathrm{NOM}}\right.$ 's $\left.\mathrm{NP}_{\mathrm{NOM}}\right]$ is nondistinct from $\mathrm{X}_{\mathrm{NOM}}$ :

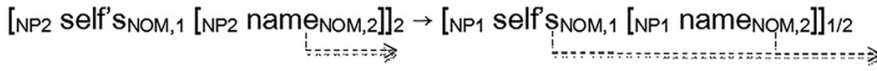

Our notion of indexical extension differs from Landau's original on two counts: first, it is not limited by the semantic (sub)class of $\mathrm{N}$ and second, it depends on the structural position of $\mathrm{X}$ (following Despić 2011, 2013, 2015) and its morphological concord with the NP it modifies (as the reflexive is morphologically an adjective; unlike the pronominal possessive, which bears genitive, shows no concord and so it does not impose its index via spreading). The extension of the possessor's referential subscript leads to a configuration prohibited by the Referential Autonomy Hierarchy in (94), where pronominal AGR is a part of a co-indexation chain with the anaphor (the reflexive possessive) acting as the argument in the agreement chain despite being lower in the autonomy hierarchy.

The AAE appears to be a universal phenomenon. Woolford (1999) argues convincingly that the core AAE, seen as a prohibition on placing the reflexive pronoun into the position of subject agreement or linking it to this position, is universally correct. Woolford shows that cases taken to be counterexamples to the AAE typically involve anaphors placed in or linked to the subject 
position which show a very specific agreement marking, frequently default 3SG or distinct from the regular subject agreement (e.g. Tamil, Albanian, Georgian). If agreement is taken to be $\varphi$ feature sharing, then the verb (via T) does not share $\varphi$-features with the anaphor. This is exemplified with the following structure from Albanian, where the anaphor is 1 SG and the verb shows $35 \mathrm{~S}:{ }^{53}$

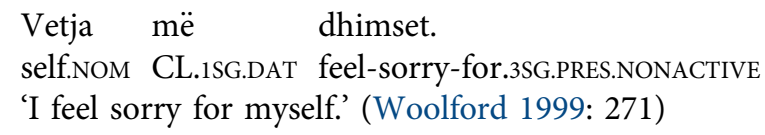

Another set of apparent counterexamples to the universal nature of Rizzi's AAE is found in languages where the anaphoric element embedded within the subject and its $\varphi$-features do not relate to $\mathrm{T}$ in any manner. Modern Greek shows this pattern, leading to the following example being grammatical:

O Giannis pisteui oti o eautos tou einai philos mou.

the Giannis thinks that the.NOM self.NOM of his is_friend of_mine

Lit. 'Giannis thinks that hisself is my friend.'

The anaphor seems to occupy the subject position and agree with T. But in Modern Greek the reflexive element seems to have a complex internal structure corresponding to a phrase: [the self [of his]] for 'himself or [the self [of my]] for 'myself. Woolford shows the role of this structure for subject agreement using arguments provided in Iatridou (1988). For instance, in Modern Greek the object may show clitic doubling, where the clitic always matches the object in $\varphi$-features. But in constructions with the anaphors in the object position, the clitic does not match the $\varphi$-features of the 'her' part of the anaphor. Instead, it shows masculine gender, apparently doubling the (default) features of 'self:

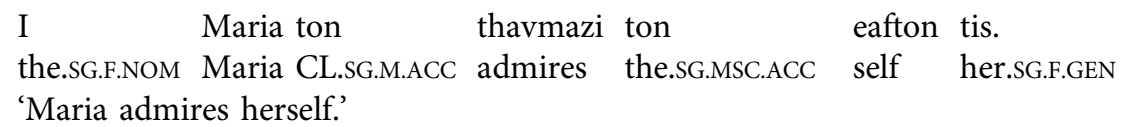

Hence the $\varphi$-feature relevant part of the anaphoric element seems to be embedded in it and it is not accessible to the $\varphi$-features of $T$ in (106) above, which apparently only access the default $\varphi$-features of 'self'. Certainly, the AAE does not hold of languages without subject agreement (e.g. Chinese, Khmer, Vietnamese, Thai). In this context, the question is whether all languages that have reflexive possessives show the Extended Anaphor Agreement Effect

${ }^{53}$ Incidentally, this Albanian example perfectly translates into a Polish construction with a DAT OE:

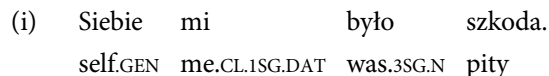
'I felt pity for myself.'

In this example T/V shows the default 3SG.N, while the Anaphor is 1st person singular. 
(EAAE), discussed for Polish in (98)-(99) and (104) above. We have not carried out a regular cross-linguistic study of this matter but a cursory search indicates that Russian follows a similar pattern: ${ }^{54}$

${ }^{\star}$ Mne dosaždaet svoj brat.

me.DAT vex.3SG self's brother

'My brother vexes me.' (Franks 1995: 253)

As (84) above shows, further embedding does not always help and the ambiguity persists; showing that the index extension may be less local. This is also true for the Obligatory Control cases:

(109) ?It considerably helped [ ${ }_{\mathrm{NP}}{ }^{1}$ the first stages of $\left[\mathrm{NP}^{2}\right.$ her ${ }_{1}$ music career $\left.]\right]\left[\mathrm{PRO}_{1}\right.$ to have an uncle in a record company]

Thus for some speakers of Polish X from (104b) can propagate its index to the maximal NP (here $\mathrm{NP}^{3}$ ), even though the structural environment is quite unambiguous:

(110) *antecedent ${ }_{\mathrm{i}} \ldots\left[\right.$ A AgrP $_{\text {anaphor }}$ agreement $\left._{\mathrm{i}} \ldots\right]$

(111) For the purpose of binding, an indexical extension [ $\mathrm{X}_{\mathrm{NOM}}$ 's $\left.\mathrm{NP}_{\mathrm{NOM}}\right]$ is non-distinct from $\mathrm{X}_{\mathrm{NOM}}$ :

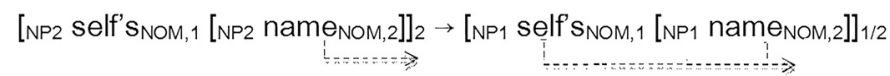

(112) For the purpose of binding, an indexical extension [X's NP] is non-distinct from $\mathrm{X}_{\mathrm{NOM}}$ :

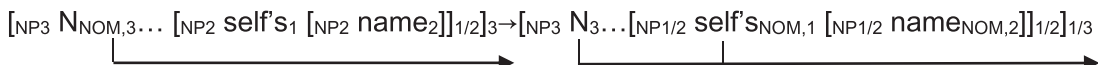

All speakers of Polish have (110) in their grammars, most speakers have (111) as a part of their grammars and exclude nominative reflexive possessives as a result of indexical extension, while the most conservative ones allow for non-local indexical extension and disallow reflexive

\footnotetext{
${ }^{54} \mathrm{We}$ are grateful to a reviewer for bringing this aspect of the analysis of the Extended AAE to our attention. The topic that must be addressed in further research is to what extent the level of embedding of the reflexive possessive is a factor in analogous constructions in Russian, Bulgarian, etc.
} 
possessives in cases other than nominative even when they are deeply embedded in nominative NPs, see (84). ${ }^{55,56}$

\section{CONCLUSIONS AND OUTLOOK}

In the process of our investigation, we have raised a number of questions with respect to the data in (1) and (3)-(5), problematic for Classical Biding Theory (Chomsky 1981, 1982, 1986; Manzini \& Wexler 1987) in view of the fact that the DAT OE can function as an antecedent either for a reflexive or pronominal possessive in an identical structural environment with an identical interpretation. We conclude that these facts can be captured under the assumption that there is one D-bound/Index which is the most dependent form bound locally and lexicalized in two different forms. We assume that this is due to a specific internal feature composition of the Dbound/Index: [ [ $\varphi][$ var:- $]$ D]. It bears a [var:_] feature, whose valuation leads to LF-relevant binding, and a defective set of $\varphi$-features with all the features being $[+\mathrm{int},-$ val $]$. This makes it similar to clitics/weak pronouns, which have the [+int, _val person] feature. The unvalued person feature is also placed on the head $v / \mathrm{T}$, which forces movement of the clitic/weak pronoun out of VP to a position at $v /$ T where the person feature is valued (Béjar \& Rezac 2003; Franks 2017, forthcoming-a). We assume that the head $\left[_{[\varphi][\text { var: }]} \mathrm{D}\right]$ is also moved out of VP, though the valuation of the [_val person] feature and other $\varphi$-features piggy-backs on the valuation of the [var:_] feature. The unvalued variable feature ([var:_]) probes (upwards) for a nominal or pronominal goal with a valued [var:x] feature (Rezac 2004; Zeijlstra 2012). The entire [DP [ $[\varphi]$ [var_] $\left.\mathrm{D}]\left[{ }_{\mathrm{NP}} \mathrm{N}\right]\right]$ constituent is lexicalised as reflexive when $(\mathrm{i})\left[_{[\varphi]\left[\mathrm{var}_{-}\right]} \mathrm{D}\right]$ is adjacent to $v / \mathrm{T}$ and (ii) the [var:_] feature of $\left[{ }_{[\varphi]\left[v_{-}\right]} D\right]$ is involved in Agree with the [var:x] feature of the NP in

${ }^{55}$ A similar effect arises for the Anti-Cataphora Effect. Willim (1989: 82) reports that the following example is problematic, though many native speakers accept it as only mildly deviant:

(i) $\% \mathrm{Ta}$ recenzja książki mojego brata $\mathrm{z}_{\mathrm{i}}$ zupełnie $\mathrm{go}_{\mathrm{i}}$ załamała.

this review.NOM of_book my brother's completely him.ACC devastated

'This review of my brother's book devastated him completely.'

We presume that the scope of index propagation is a matter of speaker variation but the extent of the propagation is difficult to gauge on account of processing difficulties. Certainly, this issue deserves further empirical study.

${ }^{56}$ For those speakers who accept the reflexive possessive embedded in a complex NP (84) there is a technical way of triggering Index Raising from an embedded position. Bošković (2005) allows for an amelioration of the ban on Deep Left Branch Extraction through a 'smuggling' movement, where step (ii) precedes (i):

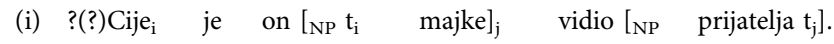
whose is he mother's saw friend

'A friend of whose mother did he see?'

(ii) ?(?)On je $\left[_{\mathrm{NP}} \text { njegove majke }\right]_{\mathrm{j}}$ vidio $\left[_{\mathrm{NP}} \text { prijatelja } \mathrm{t}_{\mathrm{j}}\right]_{\text {. }}$

he is his mother's saw friend

'He saw a friend of his mother.'

In the same vein, we propose a covert equivalent to (i-ii) to allow for long IR:

(iii) Index ... [ [NP Index [NP AP [NP N]]] .. [ [NP shape [ ${ }_{\mathrm{NP}}$ Index AP N]] 
[spec, $v \mathrm{P} / \mathrm{TP}$ ]. The antecedent must occupy its case position. Otherwise the D-bound/Index is lexicalised as a pronoun. The chain of Index Raising exhibits copy pronunciation, i.e. the tail of the chain of $\left[{ }_{[\varphi][v a r:-]} \mathrm{D}\right]$ as part of $\left[{ }_{\mathrm{DP}}\left[{ }_{[\varphi]\left[\mathrm{var}_{-}\right]} \mathrm{D}\right]\right.$ [NP $\left.\left._{\mathrm{N}}\right]\right]$ contributes to its pronunciation as either a reflexive or a pronominal. As the Agree and sharing of the [_val, person] feature between $v$ and the head $\left[_{[\varphi][\text { var: }]} \mathrm{D}\right]$ requires obligatory movement and further (covert) movement of $[[\varphi][$ var: $]$ D $]$ is optional, three empirical consequences follow immediately. First, no VP-internal dative-marked goal or benefactive argument is ever able to function as an antecedent for a reflexive form in a language showing Index Raising, as the lowest locus of lexicalisation (Nikolaeva's reflexivisation site) is placed above the case position of the goal or benefactive. Second, nominative subject orientation of reflexives and possessive reflexives follows from the lexicalisation algorithm, as [spec, $v \mathrm{P}] /[\mathrm{spec}, \mathrm{TP}]$ are local positions with respect to $v / \mathrm{T}$, where $\left[{ }_{[\varphi][v a r:-]} \mathrm{D}\right]$ is moved. Third, DAT EO has its case position in [spec, $\left.v \mathrm{P}\right]$, which means that the optional raising of $\left[_{[\varphi][\text { var:_ }]} \mathrm{D}\right]$ to T produces the dual possibility of lexicalising $\left.{ }_{\left[{ }_{[}\right][\text {[var:_ }]} \mathrm{D}\right]$ either as a reflexive (moved to $v$ ) or a pronominal (moved to T) form of the possessive. We have shown that successful binders of reflexives and reflexive possessives in Polish need not occupy the position of [spec, TP], which is reserved for nominative subjects only. We have also indicated that less than perfect results of DAT OE binding into theme $\mathrm{NOM}_{\mathrm{N}}$ are caused by the Extended Anaphor Agreement Effect, originally due to Rizzi (1990), triggered by a specific placement of the reflexive possessive as an adjunct at the edge of $\mathrm{NP}_{\mathrm{NOM}}$, its morphological concord with this NP and index propagation.

A reviewer raises the issue of the impact of our proposal on analyses of DAT OEs across the broad linguistic spectrum. The question is what is special about Polish that allows its DAT OE to function as the antecedent to both the pronominal possessive and the reflexive possessive. We can point to at least three properties of the DAT OE that must be met for a language to mimic the situation in Polish. As Witkoś et al. (2018) show certain accusative object experiences can also function as antecedents to reflexive pronouns and reflexive possessives in Polish.

First, the language must have DAT OEs which occupy a medial position in the clausal structure $([\mathrm{spec}, v \mathrm{P}])$. Second, the language must have a rich system of nominal case. But further aspects of the case system must be involved, too. We believe that the strongest evidence for DAT OEs acting as antecedents for reflexives comes in the context of the so-called non-verbal psych predicates, which select for one argument in dative (the experiencer) and the other in another case distinct from nominative (mostly genitive). Such a set-up of cases avoids the effects of AAE, which is resolved in favour of the pronominal possessor. These constructions are relatively frequent in colloquial Polish. So the verb podobać się 'appeal to' with the argument frame: [dative experiencer/nominative theme], although very frequent, does not suffice to provide evidence for the A-binding properties of the DAT OE.

Third, the language must have sufficient lexical/morphological/structural resources to express possessive elements as either reflexive or pronominal. The language in question can be either a NP-language, in terms of Bošković $(2005,2013,2014)$ and Despić $(2011,2013,2013)$ or a DP language with postnominal definiteness marking, with $\mathrm{D}$ requiring some element of its internal structure, such as the possessive, to move to the edge of DP. So all Slavic languages have DAT OEs and if they have them in the non-verbal version of the psych-predicate, these also act as A-binders for reflexive and pronominal possessives. Nikolaeva shows numerous examples from Russian, for instance: 


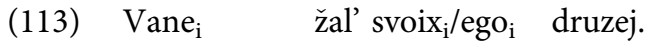

Vanja.DAT pity self s/his friends.ACC

'Vanja is sorry for his friends.' (Nikolaeva 2014: 72)

Germain analyses Lithuanian, a close cousin of Slavic languages, where they also appear:

(114) Man gaila savo mamos.

me.DAT sorry self's mother.GEN

'I feel sorry for my mom.' (Lithuanian, Germain 2017: 24)

But also Icelandic, a nominal inflection-rich Scandinavian language, seems to meet these conditions and shows the following example:

Henni Pykir [bróðr $\quad$ sinn $/{ }^{\star}$ hennar] leiðinlegar.
she.DAT thinks brother.ACC
'Self s/her fhe finds her brother boring.' (Safir 2014: 111-112)

The complicating factor here, though, could be that in Icelandic the dative subject occupies [spec, TP], see Citko et al. (2018) for a comparison of Icelandic and Polish non-nominative subjects. In principle, our proposal (or mutations thereof) should be applicable in these languages too. The next step in our research enterprise focussed on binding properties of dative experiencers is a thorough comparative study of the languages which Despić (2015) predicts to potentially allow for reflexive possessives. This task, however, is beyond the scope of this contribution.

\section{ACKNOWLEDGEMENTS}

The work on this paper has been supported by the Polish National Science Centre (NCN) grant no. 2014/15/G/HS2/04715.

\section{REFERENCES}

Abels, Klaus. 2003. Successive cyclicity, anti-locality, and adposition stranding. Doctoral dissertation. University of Connecticut.

Antonenko, Andrei. 2012. Feature-based binding and phase theory. Doctoral Dissertation. New York: Stony Brook University.

Avrutin, Sergey. 1994. The structural position of bound variables in Russian. Linguistic Inquiry 25 (4). 709-727.

Bailyn, John F.2004. Generalized inversion. Natural Language and Linguistic Theory 22. 1-50.

Bailyn, John F.2014. The syntax of Russian. Cambridge: Cambridge University Press.

Baker, Mark. 1985. The mirror principle and morphosyntactic explanation, Linguistic Inquiry 16. 373-416.

Baker, Mark. 1988. Incorporation: A theory of grammatical function changing. Chicago: University of Chicago Press. 
Béjar, Susana and Milan Rezac. 2003. Person licensing and the derivation of PCC effects. In Anna Teresa Perez-Leroux and Yves Roberge (eds.) Romance linguistics: Theory and acquisition. Amsterdam: John Benjamins. 49-62.

Béjar, Susana and Milan Rezac. 2009. Cyclic agree. Linguistic Inquiry 40. 35-73.

Belletti, Adriana and Luigi Rizzi. 1988. Psych-verbs and theta theory. Natural Language and Linguistic Theory 6. 291-352.

Boeckx, Cedric and Norbert Hornstein and Jairo Nunes. 2008. Copy-reflexive and copy-control constructions. A movement analysis. Linguistic Variation Yearbook 8. 61-100.

Bondaruk, Anna. 2017. The syntax of accusative and dative experiencer in Polish. A paper presented at the LingBaW Conference at the Catholic Univeristy of Lublin, 18-19.10.2017.

Bondaruk, Anna and Bogdan Szymanek. 2007. Polish nominativeless constructions with dative experiencers: Form, meaning and structure. Studies in Polish Linguistics 4. 61-97.

Bondaruk, Anna, Bożena Rozwadowska and Wojciech Witkowski. 2017. Passivization of Polish experiencer verbs vs. the unaccusativity hypothesis (part 1). Studies in Polish Linguistics 12. 57-73.

Bondaruk, Anna and Bożena Rozwadowska. 2018. Passives of subject experiencer verbs in Polish. A paper presented at the Formal Description of Slavic Languages conference, Georg-August-Universität Göttingen, 5-7 December.

Bošković, Željko. 2002. On multiple wh-fronting. Linguistic Inquiry 33 (3). 351-383.

Bošković, Željko. 2005. On the locality of left branch extraction and the structure of NP. Studia Linguistica 59 (1). 1-45.

Bošković, Željko. 2007. On the locality and motivation of Move and Agree: An even more minimal theory. Linguistic Inquiry 38. 589-644.

Bošković, Željko. 2012. Phases in NPs and DPs. In Ángel J. Gallego (ed.) Phases: Developing the framework. Berlin: Mouton de Gruyer. 343-383.

Bošković, Željko. 2013. Phases beyond clauses. In Lilia Schürcks, Anastasia Giannakidou and Urtzi Etxeberria (eds.) The nominal structure in Slavic and beyond. Berlin: De Gruyter Mouton. 75-128.

Bošković, Željko. 2014. More on the edge of the edge. In Cassandra Chapman, Olena Kit and Ivona Kučerová (eds.) Formal approaches to Slavic linguistics: The McMaster meeting 2013 (FASL 22). Michigan, MI: Michigan Slavic Publications. 44-66.

Burzio, Luigi. 1996. The role of the antecedent in anaphoric relations. In Robert Freidin (ed.) Current Issues in Comparative Grammar. Dordrecht: Kluwer. 1-45.

Caha, Pavel. 2009. The nanosyntax of case. Ph.D. thesis. University of Tromsø, Tromsø.

Cardinaletti, Anna and Michal Starke. 1994. The typology of structural deficiency: On the three grammatical classes. University of Venice Working Papers in Linguistics 4. 41-109.

Chomsky, Noam. 1981. Lectures on government and binding. Dordrech: Foris.

Chomsky, Noam. 1982. Some concepts and consequences of the theory of government and binding. Cambridge, Massachusetts: MIT Press.

Chomsky, Noam. 1986. Knowledge of language: Its nature, origin and use. New York: Praeger.

Chomsky, Noam. 1993. A minimalist program for linguistic theory. In Kenneth Hale and S. Jay Keyser (eds.) The view from building 20: Essays in Linguistics in Honor of Sylvain Bromberger, 1-52. Cambridge, MA: MIT Press.

Chomsky, Noam. 1995. The minimalist program. Cambridge, MA: The MIT Press.

Chomsky, Noam. 2000. Minimalist inquiries. In Roger Martin, David Michaels, Juan Uriagereka and Samuel J Keyser (eds.) Step by step: Essays on minimalist syntax in honor of Howard Lasnik. Cambridge, MA: The MIT Press. 89-156. 
Chomsky, Noam. 2001. Derivation by phase. In Michael Kenstowicz (ed.) Ken Hale: A life in language. Cambridge, MA: The MIT Press. 1-52.

Chomsky, Noam. 2008. On phases. In R. Freidin, C. P. Otero and M. L. Zubizarreta (eds.) Foundational issues in Linguistic Theory. Cambridge, MA: MIT Press. 133-166.

Chomsky, Noam. 2013. Problems of projection. Lingua 130. 33-49.

Citko, Barbara, Allison Germain and Jacek Witkoś. 2018. If you cannot agree, move on! On labels and nonnominative subjects. Glossa 3 (1). 28.

Cole, Peter, Gabriela Hermon and LI-May Sung. 1993. Feature percolation. Journal of East Asian Linguistics 2. 91-118.

Collins, Chris. 2005a. The smuggling approach to the passive in English. Syntax 8. 81-120.

Collins, Chris. 2005b. The smuggling approach to raising in English. Linguistic Inquiry 36 (2). 289-298.

Cuervo, Maria Cristina. 2003. Datives at large. Doctoral dissertation. Cambridge, MA: MIT.

Delsing, Lars-Olof. 1993. On attributive adjectives in Scandinavian and other languages. Studia Linguistica 47 (2). 105-125.

Despić, Miloje. 2011. Syntax in the absence of Determiner Phrase. Doctoral dissertation. Storrs: University of Connecticut.

Despić, Miloje. 2013. Binding and the structure of NP in Serbo-Croatian. Linguistic Inquiry 44 (2). 239-270.

Despić, Miloje. 2015. Phases, reflexives and definiteness. Syntax 18 (3). 201-234.

Dziwirek, Katarzyna. 1994. Polish subjects. Garland: New York.

Featherston, Sam. 2002. Coreferential objects in German: Experimental evidence on reflexivity. Linguistische Berichte 192. 45-484.

Franks, Steven. 1995. Parameters of Slavic Morphosyntax. Oxford: Oxford University Press.

Franks, Steven. 2017. Syntax and Spell-Out in Slavic. Bloomington, IND: Slavica Publishers.

Franks, Steven. forthcoming-a. PCC violations and their resolutions. Proceedings of FASL 26. Michigan Slavic Publications.

Franks, Steven. forthcoming-b. Microvariation in the South South Slavic Noun Phrase. Forthcoming with Slavica.

Germain, Allison. 2015. Nullifying null expletives: Accounting for EPP in Russian Impersonal and nominative in situ constructions. Proceedings of Formal Approaches to Slavic Linguistics 23. 418-438.

Germain, Allison. 2017. Non-nominative subjects in Russian and Lithuanian: Case, argument structure and anaphor binding. Seattle, University of Washington, Doctoral dissertation.

Gogłoza, Aleksandra, Paulina Łęska, Roland Meyer and Jacek Witkoś. forthcoming-a. Binding by objects in Polish double object constructions - acceptability and correlation with object order. In Proceedings of FASL 26. Ann Arbor, MI: Michigan Slavic Publications.

Gogłoza, Aleksandra, Paulina Łęska and Jacek Witkoś. forthcoming-b. Binding by Polish Experiencer Datives and the AAE. In Proceedings of FASL 27. Ann Arbor, MI: Michigan Slavic Publications.

Grewendorf, Gunter and Joachim Sabel. 1999. Scrambling in German and Japanese: Adjunction versus multiple specifiers. Natural Language and Linguistic Theory 17. 1-65.

Hasegawa, Hiroshi. 2005. Reflexive binding as agreement and its interactions with the pahse system. In: Noriko Imanishi (ed.) The world of linguistic research: A festschrift for Kinsuke Hasegawa on the occasion of his seventieth birthday. Tokyo: Kaitakusha. 53-69.

Heinat, Fredrik. 2006. Probing phrases, pronouns, and binding. The Department of English in Lund: Working Papers in Linguistics 6. 19-37.

Hellan, Lars. 1988. Anaphora in Norwegian and the theory of grammar. Dordrecht: Foris.

Hestvik, Arild. 1992. LF movement of pronouns and anti-subject orientation. Linguistic Inquiry 23. 557-594. 
Hicks, Glyn. 2009. The derivation of anaphoric relations. Amsterdam: John Benjamins. Hornstein, Norbert. 2001. Move! A minimalist theory of construal. Oxford: Blackwell.

Huang, C. T. James. 1983. On the distribution and reference of empty pronouns. Linguistic Inquiry 15. 531-574.

Iatridou, Sabine. 1988. Clitics, anaphors, and a problem of coindexation. Linguistic Inquiry 19 (4). 698-703. Ionin, Tania. 2001. Scope in Russian: Quantifier movement and discourse function. Ms. Cambridge, MA: MIT. Jimenez-Fernandez, Ángel Luis and Bożena Rozwadowska. 2016. The information structure of Dative Experiencer psych-verbs. In Bozena Cetnarowska and Marcin Kuczok and Marcin Zabawa (eds.) Various dimensions of contrastive studies. Katowice: Wydawnictwo UŚ. 100-121.

Julien, Marit. 2002. On the syntax of 'TH/EX'. Norway: Ms. University of Tromsø.

Kayne, Richard. 1985. Principles of particle constructions. In Jacqueline Guéron and Hans-Georg Obenauer and Jean-Yves Pollock (eds.) Grammatical representation. Dordrecht: Foris. 101-140.

Kayne, Richard. 1991. Romance clitics, verb movement and PRO. Linguistic Inquiry 22 (4). 647-686.

Kayne, Richard. 1994. The antisymmetry of syntax. Cambridge, MA: MIT Press.

Kayne, Richard. 2002. Pronouns and their antecedents. In Samuel Epstein and Daniel Seely (eds.) Derivation and explanation in the Minimalist Program. Oxford: Blackwell. 133-166.

Klimek, Dorota and Bożena Rozwadowska. 2004. From psych adjectives to psych verbs. Poznań Studies in Contemporary Linguistics 39. 59-72.

Landau, Idan. 2000. Elements of control: Structure and meaning in infinitival constructions. Dordrecht: Kluwer Academic Publishers.

Landau, Idan. 2006. Severing the distribution of PRO from case. Syntax 9 (2). 153-170.

Landau, Idan. 2008. Two routes of control: Evidence for case transmission in Russian. Natural Language and Linguistic Theory 26 (4). 877-924.

Larson, Richard. 1988. On the double object construction. Linguistic Inquiry 19 (3). 335-391.

Larson, Richard. 1990. Double objects revisited: Reply to Jackendoff. Linguistic Inquiry 21. 589-632.

Larson, Richard. 2014. On shell structure. London: Routledge.

Lavine, James and Steven Franks. 2008. On accusative first. In Andrei Antonenko and John F. Bailyn and Christina Y. Bethin and Jindrich Toman (eds.) Formal Approaches to Slavic Linguistics 16. Michigan Slavic Publications 16. 231-247.

Lee-Schoenfeld, Vera. 2008. Binding, phases and locality. Syntax 11(3). 281-298.

Lebeaux, David. 2009. Where does binding apply?. Linguistic Inquiry Monograph 50. Cambridge, MA: The MIT Press.

Longobardi, Giuseppe. 2001. The Structure of DPs: Some Principles, Parameters, and Problems. In Mark Baltin and Chris Collins (eds.) The Handbook of Contemporary Syntactic Theory. Blackwell. 562-603.

Manzini, Rita and Kenneth Wexler. 1987. Parameters, binding theory and learnability. Linguistic Inquiry 18. 413-444.

Marvin, Tatjana and Adrian Stegovec. 2012. On the syntax of ditransitive sentences in Slovenian. Acta Linguistica Hungarica 59. 177-203.

Matushansky, Ora. 2006. Head movement in linguistic theory. Linguistic Inquiry 37. 69-109.

May, Robert. 1985. Logical form: Its structure and derivation. Cambridge, MA: MIT Press.

Miechowicz-Mathiasen, Katarzyna and Paweł Scheffler. 2008. A corpus-based analysis of the peculiar behaviour of the Polish verb podobać się. In Gisbert Fanselow (ed.) Elements of Slavic and Germanic Grammars: A comparative view. Frankfurt/Main: Peter Lang. 89-112.

Moore, John and David M. Perlmutter. 2000. What does it take to be a dative subject? Natural Language and Linguistic Theory 18 (2). 373-416. 
Müller, Gereon. 2017. Structure removal: An argument for feature-driven Merge. Glossa: A Journal for Generative Linguistics 2 (1). 28. 1-53.

Müller, Gereon. 2018. Structure removal in complex prefields. Natural Language and Linguistic Theory 36. 219-264.

Nikolaeva, Liudmila. 2014. The secret life of pronouns. Doctoral dissertation. Cambridge, MA: MIT.

Pesetsky, David and Esther Torrego. 2001. T-to-C movement: Causes and consequences. In Michael Kenstowicz (ed.) Ken Hale, a Life in Language. Cambridge, MA: The MIT Press. 355-426.

Pesetsky, David and Esther Torrego. 2004. Tense, case, and the nature of syntactic categories. In Jacqueline Guéron and Jacqueline Lecarme (eds.) The syntax of time. Cambridge: The MIT Press.

Pesetsky, David and Esther Torrego. 2007. The syntax of valuation and the interpretability of features. In Simin Karimi, Vida Samiian and Wendy K Wilkins (eds.) Phrasal and clausal architecture: Syntactic derivation and interpretation (Linguistik Aktuell/Linguitics Today 101.). Amsterdam: John Benjamins. 262-294.

Pica, Pierre. 1987. On the nature of the reflexivization cycle. Proceedings of the North East Linguistic Society 17 (2). 483-500.

Pica, Pierre. 1991. On the interaction between Antecedent-Government and Binding: The case of longdistance reflexivization. In Jan Koster and Eric Reuland (eds.) Long Distance Anaphora. Cambridge: Cambridge University Press. 119-135.

Primus, Beatrice. 1992. Selbst - Variants of a scalar adverb in German. Linguistische Berichte Sonderheft 4. 54-88.

Progovac, Ljiljana. 1992. Long-distance reflexives without movement. Linguistic Inquiry 23 (4). 671-680.

Progovac, Ljiljana. 1993. Long-distance reflexives: Movement to Infl versus Relativized SUBJECT. Linguistic Inquiry 24 (4). 755-772.

Pylkkänen, Liina. 2002. Introducing arguments. Doctoral dissertation. Cambridge, MA: MIT.

Rappaport, Gilbert. 1986. On anaphor binding in Russian. Natural Language and Linguistic Theory 4. 97120.

Reinders-Machowska, Ewa. 1991. Binding in Polish. In J. Koster and E. Reuland (eds.) Long-distance Anaphora.Cambridge: Cambridge University Press. 137-150.

Reis, Marga. 1976. Reflexivierung in deutschen ACI-Konstruktionen: Ein transformationsgrammatisches Dilemma. Papiere zur Linguistik 9. 5-82.

Reuland, Eric. 2011. Anaphora and language design. Cambridge, MA: MIT Press.

Rezac, Milan. 2004. Elements of cyclic syntax: Agree and Merge. Toronto: University of Toronto.

Richards, Norvin. 1997. What moves where when in which language? Ph.D. dissertation. MIT.

Richards, Norvin. 1998. Principle of minimal compliance. Linguistic Inquiry 29. 599-629.

Rizzi, Luigi. 1990. On the anaphor-agreement effect. Rivista di Linguistica 2 (1). 27-42.

Rizzi, Luigi. 1997. The fine structure of the left periphery. In Haegeman, Liliane (ed.) Elements of grammar. Handbook of generative syntax. Dordrecht: Kluwer Academic Publishers. 281-337.

Rizzi, Luigi. 2014. On the elements of syntactic variation. Linguistic Variation in the Minimalist Framework, Carme. Picallo, 13-35. Oxford: Oxford. University Press.

Roberts, Ian. 1991. Excorporation and minimality. Linguistic Inquiry 22. 209-218.

Roberts, Ian. 1992. A formal account of grammaticalisation in the history of romance futures. Folia Linguistica Historica 13 (1/2). 219-258.

Roberts, Ian. 1993. Verbs and diachronic syntax. Dordrecht: Kluwer Academic Publishers.

Roberts, Ian. 2009. Agreement and head movement. Cambridge, MA: MIT Press.

Safir, Ken. 2004. The syntax of anaphora. Oxford: Oxford University Press.

Safir, Ken. 2014. One true anaphor. Linguistic Inquiry 45 (1). 91-124. 
Sportiche, Dominique. 1996. Clitic constructions. In Johan Rooryck and Laurie Ann Zaring (eds.) Phrase Structure and the Lexicon. Dordrecht: Kluwer Academic Publishers. 213-276.

Starke, Michal. 2002. The day syntax ate morphology. Class taught at the EGG summer school, Novi Sad. Stegovec, Adrian. 2016. What we aren't given: Selection and ditrasitive passives in Slovenian. Paper presented at the Formal Approaches to Slavic Linguistics, Cornell University, May 13th 2016.

Szabolcsi, Anna. 1983. The possessor that ran away from home. The Linguistic Review 3 (1). 89-102.

Tajsner, Przemysław. 1990. Case marking in English and Polish: A government and binding study. Doctoral dissertation. Poznań: Adam Mickiewicz University.

Tajsner, Przemysław. 2008. Aspects of the grammar of focus: A minimalist view. Frankfurt am Main: Peter Lang.

Travis, Lisa. 1984. Parameters and effects of word order variation. Doctoral dissertation. Cambridge, MA: MIT.

Vicente, Luis. 2007. The syntax of heads and phrases: A study of verb (phrase) fronting. Leiden University: Leiden.

Vikner, Sten. 1985. Parameters of binder and of binding category in Danish. Working Papers in Scandinavian Syntax 23. 1-61.

Wiland, Bartosz. 2016. Le Charme Discret of Remnant Movement: Crossing and nesting in Polish OVS sentences. Studies in Polish Linguistics 11 (3). 133-165.

Willim, Ewa. 1989. On word-order: A government-binding study of English and Polish. Kraków: Wydawnictwo Uniwersytetu Jagiellońskiego.

Willim, Ewa. 2018. On the dative experiencer in Polish reflexive impersonal middles. Paper presented at Berlin Dative Days workshop, 24-25 May 2018.

Witkoś, Jacek. 1993. Some aspects of phrasal movement in English and Polish. Doctoral dissertation. Poznań: Adam Mickiewicz University.

Witkoś, Jacek. 1998. The syntax of clitics: Steps towards a Minimalist Account. Poznań: Motivex.

Witkoś, Jacek. 2008. On the correlation between A-type scrambling and Weak Crossover Effects. Studia Anglica Posnaniensia 44. 297-328.

Witkos, Jacek, Dominika Dziubała-Szrejbrowska and Paulina Łęska. 2018. Binding as agree and index raising: The case of Polish accusative object experiencers. In Poznań Studies in Contemporary Linguistics 54. 469-507.

Witkoś, Jacek, Paulina Łęska, Dominika Dziubała-Szrejbrowska and Aleksandra Gogłoza. 2020. Bind me tender, bind me do! Dative and accusative arguments as antecedents for reflexives in Polish. Berlin: Peter Lang.

Woolford, Ellen. 1999. More on the Anaphor Agreement effect. Linguistic Inquiry 30 (2). 257-287.

Woolford, Ellen. 2006. Lexical case, inherent case, and argument structure. Linguistic Inquiry 37 (1). 111130.

Zeijlstra, Hedde. 2012. There is only one way to agree. The Linguistic Review 29. 491-539.

Zubkov, Petr. 2018. The grammar of binding. A study with reference to Russian. Doctoral dissertation. LOT: Utrecht. University of Utrecht.

Zwart, Jan-Wouter. 2002. Issues relating to a derivational theory of binding. In Samuel Epstein and Daniel Seely (eds.) Derivation and explanation in the Minimalist Program. Oxford: Blackwell. 269-304.

Żychliński, Sylwiusz. 2013. On some aspects of the syntax of Object Experiencers in Polish and English.

Doctoral dissertation. Poznań: Adam Mickiewicz University. 